RAFAEL INDUZZI DREWS

Redes contratuais com função de distribuição

Tese de Doutorado

Orientadora: Professora Titular Paula Andrea Forgioni

UNIVERSIDADE DE SÃO PAULO

FACULDADE DE DIREITO

São Paulo - SP

2017 
RAFAEL INDUZZI DREWS

\section{Redes contratuais com função de distribuição}

Tese apresentada à Banca Examinadora do Programa de Pós-Graduação em Direito da Faculdade de Direito da Universidade de São Paulo, como exigência parcial para obtenção do título de Doutor em Direito, na área de concentração Direito Comercial, sob a orientação da Professora Titular Dra. Paula Andrea Forgioni.

UNIVERSIDADE DE SÃO PAULO

FACULDADE DE DIREITO

São Paulo - SP 
Catalogação da Publicação

Serviço de Biblioteca e Documentação

Faculdade de Direito da Universidade de São Paulo

Drews, Rafael Induzzi

Redes contratuais com função de distribuição / Rafael Induzzi Drews; orientadora Paula Andrea Forgioni -- São Paulo, 2017.

$236 \mathrm{p}$.

Tese (Doutorado - Programa de Pós-Graduação em Direito Comercial) - Faculdade de Direito, Universidade de São Paulo, 2017.

1. Redes contratuais. 2. Distribuição. 3. Franquia. 4. Concessão comercial. 5. Interesse da Rede. I. Forgioni, Paula Andrea, orient. II. Título. 
BANCA EXAMINADORA

Prof. Dr.

Prof. Dr.

Prof. Dr.

Prof. Dr.

Prof. Dr. 


\section{AGRADECIMENTOS}

Agradeço imensamente à minha orientadora, Professora Paula Andrea Forgioni, pelo exemplo de seriedade e competência acadêmica, pela orientação dedicada e por ter me incentivado de forma decisiva quando, por um momento, deixei de acreditar que seria possível completar este trabalho.

Aos ilustres Professores Rodrigo Octavio Broglia Mendes e Judith Martins-Costa, que fizeram parte de minha banca qualificação, agradeço pelas críticas que deram uma direção mais objetiva ao meu projeto, além dos debates que permitiram o amadurecimento da minha linha de pesquisa.

Ao Professor Erasmo Valladão Azevedo e Novaes França agradeço pelos precisos ensinamentos, pelas oportunidades e pelo convívio sempre prazeroso.

Aos queridos amigos que fiz na Universidade de São Paulo, Luiz Daniel Haj Mussi, Ademar Vidal Neto, Caio Machado Filho, Maria do Céu Marques Rosado, Ruy Pereira Camilo Jr., André Okumura e Leandro Saito, agradeço a amizade e os momentos tão memoráveis que ficarão para sempre marcados na minha vida.

À minha mãe, Edina Induzzi Drews, e às minhas irmãs, Simonne e Cláudia, por sempre transmitirem palavras de otimismo e esperança.

Aos meus amigos da Procuradoria Geral do Estado do Espírito Santo, Francisco Augusto Teixeira de Carvalho, Douglas Gianordoli Santos Jr. e José Alexandre Rezende Bellote, pelo apoio constante.

E, por último, e mais importante, agradeço a Erica Pimentel, amor da minha vida, pelo apoio carinhoso e incondicional. Sem ela a conclusão deste trabalho simplesmente não seria possível. 
Para o meu pai, José Carlos Drews (in memorian), exemplo de compromisso e honestidade.

Para os meus amados filhos, "Zé Grandão" e "Luluga", com todo o meu amor. 


\section{RESUMO}

DREWS, Rafael Induzzi. Redes contratuais com função de distribuição. 2017, 236 f. Tese de Doutorado: Faculdade de Direito, Universidade de São Paulo, São Paulo.

A presente tese versa sobre redes contratuais com função de distribuição, assim entendidas aquelas formadas por contratos de distribuição, concessão comercial - regidos pela Lei 6.729/79 - e franquia. Nessas redes, o organizador ou líder (fornecedor, fabricante ou franqueador) mantém contratos bilaterais homogêneos com cada um dos distribuidores, concessionários e franqueados, os quais, por sua vez, não mantêm relação contratual formal entre si. Ao líder são reservadas diversas prerrogativas contratuais que lhe possibilitem organizar e controlar o funcionamento da rede, com vistas a uma maior eficiência global e ao fortalecimento da marca. O trabalho procura definir essas redes e compreender como o direito, em especial o direito contratual, deve tratá-las. Sustenta-se que elas não se esgotam nos contratos bilaterais que as formam, sendo dotadas de uma dimensão coletiva que, embora não se amolde às categorias tradicionais do direito privado, é relevante para o direito contratual. Apresenta-se contribuição à identificação de vetores para o tratamento jurídico das redes.

Palavras-chave: Redes contratuais. Distribuição. Franquia. Concessão comercial. Interesse da rede. 


\begin{abstract}
DREWS, Rafael Induzzi. Contractual networks with a distribution function. 2017, $236 \mathrm{f}$. Doctorate Thesis: Faculty of Law, University of São Paulo.

This thesis deals with contractual networks with a distribution function, wich are understood as those formed by distribution agreements, commercial concession - governed by Law 6.729 / 79 - and franchise. In these networks, the organizer or leader (supplier, manufacturer or franchisor) maintains homogeneous bilateral contracts with each of the distributors, dealers and franchisees, who, in turn, have no formal contractual relationship with each other. To the leader are reserved several contractual prerogatives that allow him to organize and control the operation of the network, with a view to greater global efficiency and the strengthening of the brand. The work seeks to define these networks and to understand how law, especially contractual law, must deal with them. It is argued that they are not exhausted in the bilateral contracts that form them, and are endowed with a collective dimension that, although it does not fit into the traditional categories of private law, is relevant to contractual law. A contribution to the identification of vectors for the legal treatment of networks is presented.
\end{abstract}

Keywords: Contractual networks. Distribution. Franchise. Commercial concession. Interest of the network. 


\section{RÉSUMÉ}

DREWS, Rafael Induzzi. Les réseaux contractuels à fonction de distribution. 2017, $236 \mathrm{f}$. Thèse de Doctorat: Faculté de Droit, Université de São Paulo.

Cette thèse porte sur les réseaux contractuels à fonction de distribution, entendus comme ceux qui sont constitués par les accords de distribution, la concession commerciale - régie par la Loi 6.729 / 79 - et la franchise. Dans ces réseaux, l'organisateur ou le leader (fournisseur, fabricant ou franchiseur) entretient des contrats bilatéraux homogènes avec chacun des distributeurs, concessionnaires et franchisés qui, à leur tour, n'ont aucune relation contractuelle formelle entre eux. Pour le leader sont réservées plusieurs prérogatives contractuelles qui lui permettent d'organiser et de contrôler le fonctionnement du réseau, en vue d'une plus grande efficacité globale et le renforcement de la marque. Le travail vise à définir ces réseaux et à comprendre comment le droit, en particulier le droit contractuel, doit les traiter. Il est soutenu qu'ils ne sont pas épuisés dans les contrats bilatéraux qui les forment et sont dotés d'une dimension collective qui, bien qu'elle ne rentre pas dans les catégories traditionnelles de droit privé, est pertinente au droit contractuel. Une contribution à l'identification des vecteurs pour le traitement juridique des réseaux est présentée.

Mots-clés: Réseaux contractuels. Distribution. La franchise. Concession commerciale. Intérêt du réseau. 


\section{SUMÁRIO}

INTRODUÇÃO. 13

\section{CAPÍTULO 1 - VETORES DE PARTIDA PARA A ANÁLISE DO} FENÔMENO DAS REDES CONTRATUAIS ............................................. 16

$1.1 \mathrm{Da}$ decomposição organizacional à recomposição contratual....................................16

$1.2 \mathrm{O}$ conceito de rede como ponto em aberto. As redes como ponto de intersecção de

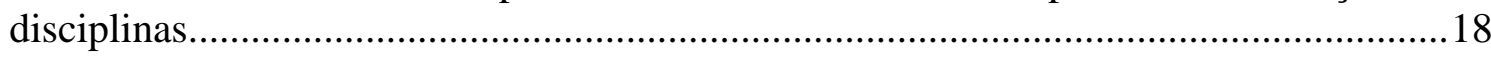

1.3 A Economia dos Custos de Transação e as redes como híbridos .............................19

1.4 As contribuições da sociologia econômica: redes como forma específica de

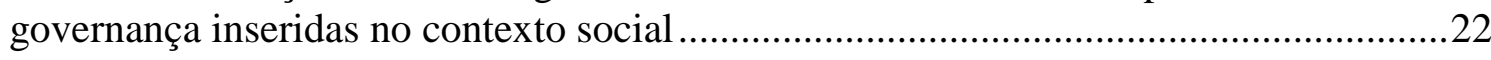

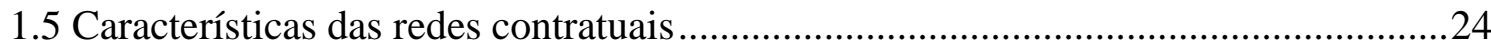

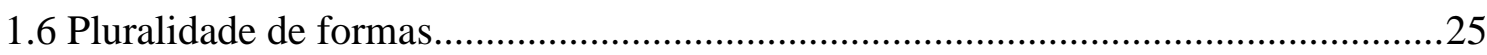

1.7 Breve tipologia: redes formadas por contratos bilaterais, plurilaterais e redes mistas .26

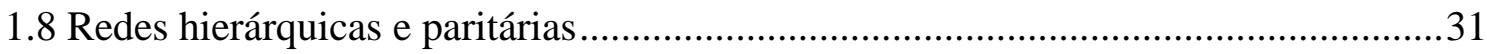

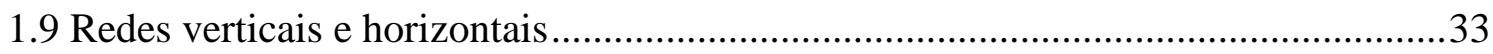

1.10 Redes contratuais com função de distribuição: precisão terminológica e noção .....33

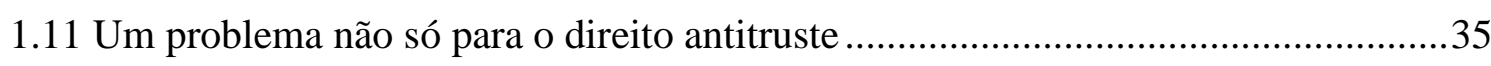

CAPÍTULO 2 - REDES COM FUNÇÃO DE DISTRIBUIÇÃO NA

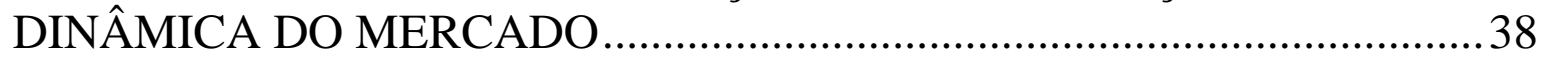

2.1 Função econômica e organização das redes com função de distribuição ....................38

2.1.1 Um complexo instrumento para o escoamento da produção ...............................38

2.1.2 Um instrumento para a competição ............................................................40

2.1.3 Um instrumento para a especialização e para separação de riscos e de

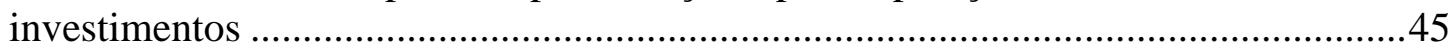

2.2 Dinâmica das redes com função de distribuição ......................................................47

2.2.1 A tensão entre interesse comum e interesses individuais ...............................47

2.2.2 Segue: entre unidade e pluralidade ................................................................50

2.2.3 Uma governança dirigida à eficiência global................................................53

2.2.3.1 A centralização de poder de decisão no líder da rede .................................54

2.2.3.2 O papel das restrições verticais na formatação da rede ...............................56

2.2.3.3 Organização da rede e edição de normas comuns......................................59

2.2.3.4 O controle do funcionamento da rede pelo líder........................................62

2.2.3.5 Interdependência e colaboração entre os membros da rede ..........................65

A) Colaboração pela troca de informações e conhecimento .................................66 
B) Colaboração por meio de atos e serviços comuns 68

C) Colaboração por meio de centros de parcitipação coletiva. $\mathrm{O}$ exemplo das

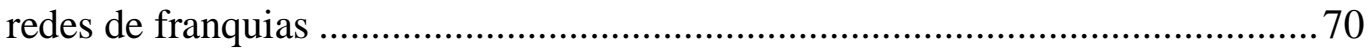

D) Segue: o papel das associações de distribuidores ........................................ 72

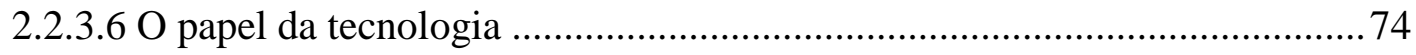

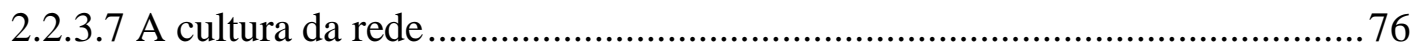

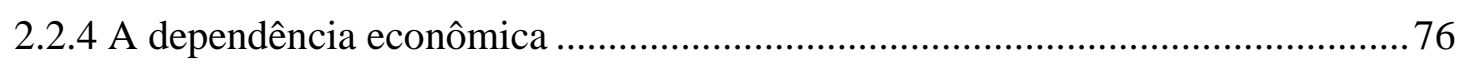

2.2.4.1 A dependência econômica em um contexto de rede.................................. 79

\section{CAPÍTULO 3. AS REDES COM FUNÇÃO DE DISTRIBUIÇÃO PARA} ALÉM DOS LIMITES COGNITIVOS DO CONTRATO

3.1 Problematização: redes, um novo conceito do direito privado? ............................... 81

$3.2 \mathrm{O}$ ponto de partida: a insuficiência dos dados legislativos nacionais ........................ 82

3.3 Redes com função de distribuição e categorias tradicionais do direito privado ......... 83

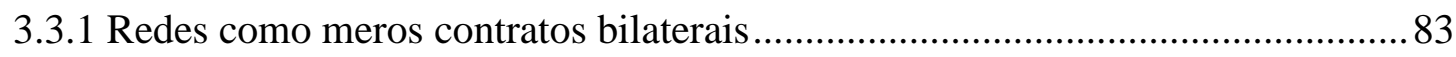

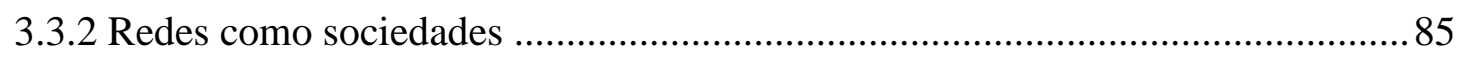

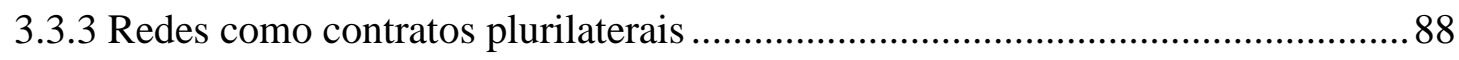

3.3.4 Segue: as redes como relação jurídica intraeficacial (gestão de negócios) e como contratos bilaterais com efeitos plurilaterais .......................................................... 90

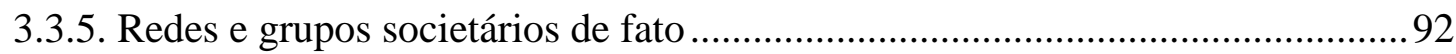

3.3.6 Redes e contratos coligados ou conexos .........................................................96

3.4 Conclusão parcial: as redes com função de distribuição para além dos limites

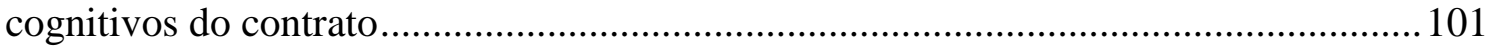

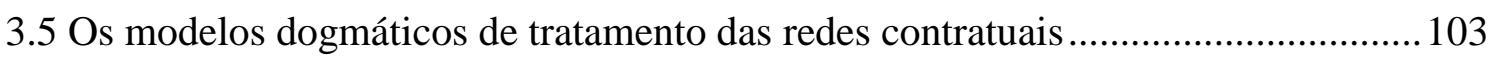

3.5.1 A negação de um tratamento específico para as redes..................................... 103

3.5.2 A teoria relacional: redes entre individualismo e comunitarismo ..................... 104

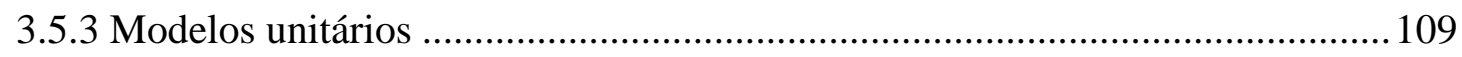

3.5.3.1 Möschel e Rohe: o contrato de rede (Netzvertrag) .................................. 109

3.5.3.2 O contratto di rete italiano .................................................................... 114

3.5.4. Modelos estruturados em torno do fim da rede ............................................ 116

3.5.4.1 Teubner e a rede entre mercado e hierarquia. Fim da rede (Netzzweck) e dupla atribuição seletiva ................................................................................. 116

3.5.4.2 Lorenzetti e a teoria sistêmica ............................................................. 118

3.5.4.3 Grundmann: o tratamento das redes a partir dos instrumentos dogmáticos

existentes. Netzzweck e cláusulas gerais......................................................... 120

3.5.5. A contribuição Malzer: a teoria do direito da organização contratual

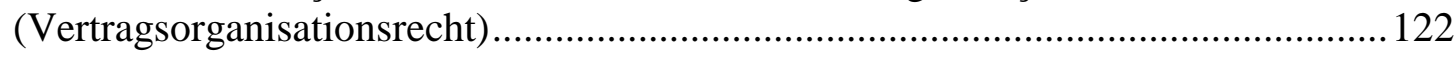

3.5.6 Conclusões. Proposta de definição das redes contratuais com função de distribuição. 


\section{CAPÍTULO 4. A REDE EM AÇÃO: TRÊS VETORES FUNDAMENTAIS} PARA O TRATAMENTO JURÍDICO DAS REDES .....................................125

$4.1 \mathrm{O}$ dilema do direito: entre liberdade, eficiência e proteção ....................................125

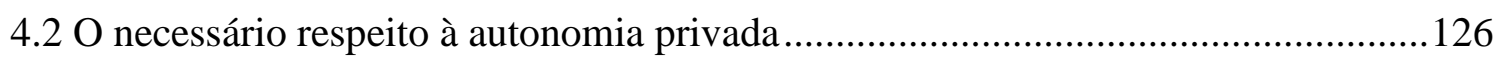

4.3 Segue: a auto-regulação no nível macro. Minutas padrão e Códigos de Conduta. O

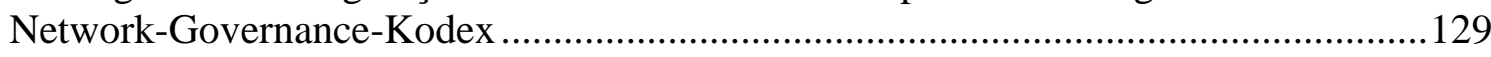

4.4 A fim ou interesse da rede como elemento de catalização .....................................134

4.4.1 Precisão inicial: a noção de interesse ................................................................134

4.4.2 Interesse "da rede"? O interesse da rede como interesse coletivo dos seus

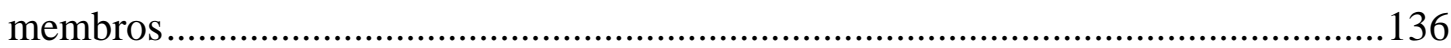

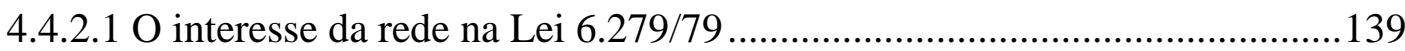

4.4.2.2 A perspectiva dos agentes do mercado ...................................................142

4.4.2.3 A perspectiva da jurisprudência ............................................................. 143

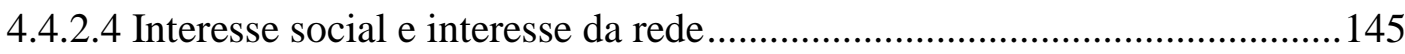

$4.5 \mathrm{O}$ problema da justificação dogmática do fim e do interesse da rede .......................148

4.5.1 A função econômica (causa) dos contratos que formam a rede: uma abordagem

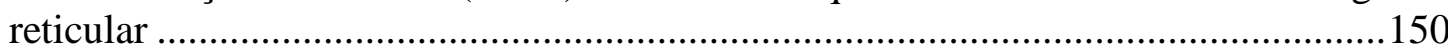

4.5.2 O caráter grupal e comunitário dos contratos que formam a rede ....................159

4.6 Interesse da rede, boa-fé objetiva e deveres contratuais ........................................161

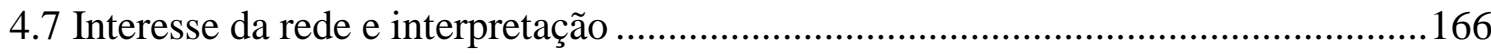

4.8. A necessária proteção das legítimas expectativas no interior da rede .....................168

4.8.1 Redes, confiança pessoal e confiança sistêmica ...............................................170

4.8.2 Usos e costumes e redes como comunidades contratuais ................................174

CONCLUSÃO

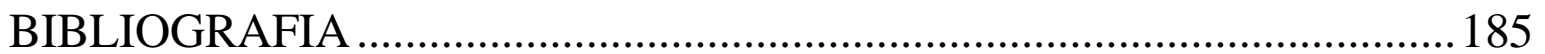




\section{INTRODUÇÃO}

"A dogmática jurídica do contrato parece hoje voltar a ser um palco de acesa discussão" .

Essas palavras, utilizadas por CARNEIRO DA FRADA há mais de duas décadas, parecem cada vez mais atuais. Já ficou para trás o tempo de relativa estagnação em que a doutrina comercialista limitava o seu esforço à sistematização dos tipos contratuais legais ou sociais ${ }^{2}$ e à explicitação dos direitos e deveres das partes ${ }^{3}$.

Essa visão, radicada na concepção de que o contrato é um ato isolado, estabelecido entre duas partes e que projeta efeitos exclusivamente sobre elas, tornou-se insuficiente. Foi superada pela força motriz das necessidades econômicas e por operações complexas realizadas a partir de verdadeiras redes contratuais, que congregam diversas empresas independentes em torno de um objetivo comum. O ponto, portanto, é que "a teoria clássica tratou o contrato como um continente demasiadamente isolado, quando ele somente pode ser uma ilha de um arquipélago animado por uma vida coletiva"4.

O objetivo da presente tese é estudar parte desse fenômeno, mais especificamente as redes contratuais formadas por contratos de distribuição, franquia e concessão comercial.

Embora esses contratos apresentem especificidades - e corporificarem tipos autônomos -, a semelhança - senão identidade - de função econômica justifica o tratamento conjunto das redes por eles formadas. Trata-se de contratos voltados à promoção do escoamento de bens ou serviços. O contrato de distribuição é definido como "bilateral, sinalagmático, atípico e misto, de longa duração e de caráter estável, que encerra um acordo

\footnotetext{
${ }^{1}$ MANUEl A. CARneIRo DA FradA, Contrato e deveres de proteção, Universidade de Coimbra: Coimbra, 1994, p. 13.

${ }^{2}$ Como explica Pedro Pais de VAsconcelos (Contratos atípicos, Almedina: Coimbra, 2002, p. 59-64), “[o]s tipos contratuais podem ser legais ou extralegais. Legais são os que constam tipificados na lei; extralegais são os que estão tipificados na prática. Os tipos legais de contratos não esgotam os tipos contratuais. Para além dos que constam tipificados na lei, outros tipos contratuais existem na prática da vida e da contratação. [...] Estes tipos [...] podem designar-se adequadamente por "tipos sociais"'.

${ }^{3}$ PAUla A. Forgioni, Contratos empresariais. Teoria geral e aplicação, São Paulo: RT, 2015, p. 34.

${ }^{4}$ Michel CABRILlaC, Remarques sur la théorie génerale du contrat et les créations récentes de la pratique commerciale, In: Mélanges dédiés à Gabriel Marty, Toulouse: Université des sciences sociales de Toulouse, 1978, p. 235-254 apud VALÉRIE MARX, La dimension collective des réseaux de distribution, Paris: Atelier national de reproduction des thèses, 2008, p. 17.
} 
vertical, pelo qual um agente econômico (fornecedor) obriga-se ao fornecimento de certos bens ou serviços a outro agente econômico (distribuidor), para que este os revenda, tendo como proveito econômico a diferença entre o preço de aquisição e de revenda e assumindo obrigações voltadas à satisfação das exigências do sistema de distribuição do qual participa"5. Contratos de concessão comercial nada mais são do que contratos de distribuição de veículos automotores, peças e acessórios, que contam com um regime especial previsto na Lei n. 6.729/79. Nos contratos de franquia, por sua vez, a nota distintiva recai sobre a transferência de tecnologia, know how, a licença de uso da marca e sobre a cobrança de remuneração pela integração ao sistema, conforme tipificação da Lei $8.955 / 1994^{6}$. Mas a sua função econômica também se dirige à distribuição de bens ou serviços ${ }^{7}$.

Mas como o direito deve tratar as redes contratuais com função de distribuição? As categorias tradicionais do direito privado são capazes de captá-las adequadamente? Que contribuições podem ser apresentadas para o tratamento jurídico das redes com função de distribuição?

A hipótese central que se pretende desenvolver é que a análise das questões derivadas das redes contratuais com função de distribuição deve partir do reconhecimento de sua dimensão coletiva e dinâmica, evitando-se uma análise atomística centrada exclusivamente nos contratos bilaterais.

O trabalho está dividido da seguinte forma.

O capítulo 1 tem por objeto apresentar o arcabouço conceitual necessário à compreensão das redes contratuais e de sua problemática.

\footnotetext{
${ }^{5}$ PaUla A. Forgioni, Contrato de distribuição, São Paulo: RT, 2014, 3 a ed., p. 81-82.

${ }^{6}$ Eis a definição do contrato de franquia segundo o artigo $2^{\circ}$ da Lei: "Franquia empresarial é o sistema pelo qual um franqueador cede ao franqueado o direito de uso de marca ou patente, associado ao direito de distribuição exclusiva ou semi-exclusiva de produtos ou serviços e, eventualmente, também ao direito de uso de tecnologia de implantação e administração de negócio ou sistema operacional desenvolvidos ou detidos pelo franqueador, mediante remuneração direta ou indireta, sem que, no entanto, fique caracterizado vínculo empregatício."

${ }^{7}$ Cf. Paula A. Forgioni, Contrato de distribuição, cit., p. 72-74; FÁBIo Konder Comparato, Franquia e concessão de venda no Brasil: da consagração ao repúdio? In: FÁBIO KONDER COMPARATO, Ensaios $e$ pareceres de direito empresarial, Rio de Janeiro: Forense, 1978, p. 372-392, p. 374.
} 
No capítulo 2 analisam-se a função econômica e a dinâmica das redes contratuais com função de distribuição. Para tanto, são tratados os pontos marcantes (existência de interesses individuais e comuns, a centralização de poder conferida ao organizador da rede, a existência de uma política comercial e de uma imagem comum, a participação coletiva dos membros em maior ou menor grau, etc). A proposta, nesse ponto, é tentar demonstrar que, para cumprir a sua função econômica, as redes são estruturadas e funcionam a partir de uma lógica colaborativa e conflituosa de unidade na pluralidade. Ou seja: ao mesmo tempo em que são formadas por inúmeros atores independentes (pluralidade), possuem também uma feição socioeconômica coletiva (unidade), ainda que assimétrica.

O capítulo 3 trata da captação das redes com função de distribuição pelo direito. Pretende-se demonstrar que a semântica e as categorias contratuais tradicionais não conseguem captar as formas contratuais colaborativas e muito menos as formas colaborativas plurais, de que são exemplo as redes com função de distribuição. Serão analisadas, assim, as principais tentativas de enquadramento dogmático das redes e os modelos teóricos propostos para o seu tratamento.

O capítulo 4 procurará apresentar vetores dogmáticos para o tratamento jurídico das redes com função de distribuição. Partindo das conclusões alcançadas no capítulo anterior, o seu objetivo é construir critérios para o tratamento das questões internas à rede. Papel central é atribuído ao fim ou interesse da rede (Netzzweck). Inicialmente, cumpre desvendar esse critério e delimitar as suas potencialidades e limitações dogmáticas, demonstrando as suas particularidades perante figuras dogmáticas semelhantes e analisando a legislação brasileira pertinente. Feito isso, será necessário analisar até que ponto é possível falar em direitos e deveres contratuais decorrentes da existência da rede. Importa aqui investigar se a inserção de um contrato em um contexto de rede com função de distribuição pode implicar direitos e deveres especiais em relação àqueles já derivados do próprio contrato, seja em relação ao outro contratante, seja em relação a integrantes da rede não contratantes entre si. Será possível, assim, falar em deveres intensificados de cooperação, lealdade, manutenção da rede, informação, de igualdade de tratamento, entre os membros da rede? 


\section{CONCLUSÃO}

É chegada a hora de apresentarmos as conclusões que alcançamos ao longo do caminho, as quais, evidentemente, não devem ser tidas como peremptórias, mas como contribuições ao debate, que, convenhamos, ainda está em seu início.

Nesta tese procuramos desvendar o fenômeno das redes contratuais com função de distribuição e apresentar, sob o ponto de vista teórico e prático, elementos para o seu tratamento jurídico.

Se há um ponto que devemos ressaltar desde já é que as redes contratuais com função de distribuição constituem um instrumento de atuação no mercado. $\mathrm{O}$ jurista que pretenda compreendê-las deve partir dessa premissa fundamental, sob pena de incorrer em grave erro metodológico.

O ambiente do mercado revela que as redes com função de distribuição corporificam um complexo instrumento de escoamento da produção. Embora constituídas por empresas independentes, acabam por se apresentar no mercado como uma unidade econômica e concorrencial, que tem na figura do líder (fabricante, importador ou franqueador) o seu grande administrador. É ele quem, dotado de prerrogativas contratuais e fáticas, direciona o comportamento dos seus distribuidores, fixando políticas comerciais e de marketing uniformes, de forma a vencer os desafios da concorrência.

As redes com função de distribuição não se esgotam, portanto, nas relações entre líder e distribuidores. São, em verdade, formas colaborativas plurais. Há todo um conjunto de relações jurídicas e econômicas que lhes confere uma dimensão coletiva, a qual, entretanto, nem sempre é harmoniosa. É que é da natureza mesmo dessas redes que seus membros - juridicamente indepententes, mas economicamente interdependentes - busquem satisfazer os seus interesses individuais, embora colaborem em grau variado pelo sucesso do empreendimento comum. Afinal, se a rede vai bem, a marca comercializada vai bem e todos vão bem. É por isso que se diz que elas são caracterizadas pelo paradoxo da unidade na pluralidade, da colaboração e competição.

As redes contratuais com função de distribuição não constituem um conceito 
jurídico - ao menos positivado - no direito brasileiro. Os dados legislativos nacionais são insuficientes para uma definição precisa.

Ao longo da pesquisa pudemos perceber que as categorias tradicionais do direito privado, em especial do direito contratual, também não são aptas a captá-las. A dicotomia contratos de troca, contratos de sociedade são insuficientes para absorver toda a sua complexidade. As redes não são meros contratos bilaterais. Também não são sociedades, contratos plurilaterais ou contratos coligados.

São amplamente conhecidas as dificuldades de análise jurídica (sob o ponto de vista contratual) das redes contratuais com função de distribuição. A verdade é que elas transbordam a semântica contratual tradicional e, portanto, os seus limites cognitivos. Embora dotadas de um núcleo contratual, nem tudo o que as compõe é contrato. Nelas se observa certa relativização do papel do contrato e uma porção metacontratual ou paracontratual - consistente em um plexo de vínculos informais, jurídicos, econômicos e sociais e uma indissociável coexistência de dimensões individual e coletiva - da qual surgem novas ordens de expectativas não geralmente derivadas de relações contratuais comuns.

É compreensível, portanto, que a literatura - nacional e estrangeira -, ainda não tenha chegado a uma definição ou mesmo a um modelo teórico adequado para trata-las adequadamente. Essa falta de clareza dogmática inflelizmente não nos permitiu avançar muito sobre terreno tão árido, apesar do esforço na pesquisa empreendida.

Diante dessa dificuldade o caminho percorrido foi o de tentar desenvolver uma definição instrumental de redes com função de distribuição, que reconheça a sua dimensão coletiva, e que possa guiar desenvolvimentos futuros. Não se trata, é claro, de um conceito acabado. É antes uma definição que busca retratar os principais elementos dessa forma organizativa, notadamente a junção de empresas em torno de um fim ou interesse comum.

Além de uma definição instrumental, portanto, esta tese contribui com o debate jurídico nacional na medida em que apresenta três vetores essenciais ao tratamento jurídico das redes com função de distribuição. O primeiro é a necessidade de respeito à autonomia privada; o segundo o reconhecimento do fim ou interesse da rede como elemento de 
catalização dos contratos; o terceiro, a necessidade de proteger as legítimas expectativas que decorrem da integração dos distribuidores à rede.

Nada obstante essas contribuições, a conclusão final é que o tema objeto deste trabalho envolve questões que permanecem em aberto, demandando desenvolvimentos futuros.

Em nossa opinião, entretanto, o caminho a percorrer na resolução dessas questões em aberto deve ser aquele que, reconhecendo a dimensão coletiva da rede, procure um adequado equilíbrio entre a liberdade dos agentes, a eficiência das formas organizativas reticulares e a proteção de valores jurídicos. 


\section{BIBLIOGRAFIA}

ADAMEK, Marcelo Vieira Von. Abuso de minoria em direito sociário. São Paulo: Malheiros, 2014.

AKERLOF, Geoger A. The Market for "Lemons: Quality Uncertainty and the Market Mechanism. In: The Quarterly Journal of Economics.Vol. 84, No. 3. (Aug., 1970), p. 488500 .

AKREMI, Assâad El; MIGNONAC, Karim; PERRIGOT, Rozenn. Opportunistic behaviors in franchise chains: the role of cohesion among franchisees. In: Strategic Management Journal, 31 (2010), p. 930-948.

ALVINO, Ilario. Il lavoro nelle reti di imprese: profili giuridici. Milano: Giuffrè, 2014.

AMIEL-COSME, Laurence. La théorie institutionnelle du réseau. In: Aspects actuels du droit des affaires - Mélanges enl'honneur de Yves Guyon. Paris: Dalloz, 2003.

Les réseaux de distribution. Paris: L.G.D.J., 1995.

AMSTUTZ, Marc. The constitution of contractual networks. In: AMSTUTZ, Marc; TEUBNER, Gunther (Coord.). Networks: legal issues of multilateral co-operation. Oxford: Hart Pub, 2009. p. 347-384.

DEAKIN, Simon. The Return of the Guild? Network relations in hisotical perspective. In: AMSTUTZ, Marc; TEUBNER, Gunther. Networks: legal issues of multilateral cooperation. Oxford: Hart Pub, 2009. p. 53-73.

ANTUNES, José A. Engrácia. Os grupos de sociedades, Coimbra: Almedina, 1993.

A 'consuetudo mercatorum' como fonte do direito comercial. In: Revista de Direito Mercantil, Industrial, Econômico e Financeiro, n. 146, 2007, p. 7-22. 
. Estrutura e responsabilidade da empresa: o moderno paradozo regulatório. In: CUNHA, Alexandre dos Santos. (Coord.) O direito da empresa e das obrigações e o novo Código Civil brasileiro. São Paulo: Quartier Latin, 2006. p. 18-64.

ARESTI, Paulo Martín. Signos distintivos y redes de distribuición. In: RUIZ PERIS, Juan Ignacio (Coord.). Nuevas Perspectivas Del Derecho De Redes Empresariales. Valencia: Tirant Lo Blanch, 2012, p. 547-572.

ARKELOF, George A. The market for "lemons": quality uncertainty and the market mechanism. In: The quaterly journal of economics, v. 84, n.3, 1970, p. 488-500.

ARROW, Kenneth J. Uncertainty and the Welfare Economics of Medical Care. The American Economic Review, Vol. 53, No. 5. (Dec., 1963), p. 941-973.

ARRUÑADA, Benito; GARICANO, Luis; VÁZQUEZ, Luis. Contractual Allocation of Decision Rights and Incentives: The Case of Automobile Distribution. In: Journal of Law, Economics, and Organization n. 17(1): 2001, p. 256-283.

ASCARELLI, Tullio. O contrato plurilateral. In: Problemas das sociedades anônimas e direito comparado. São Paulo: Saraiva, 1945, p. 273-332.

ASENSIO, Carlos Gomes. La gobernanza de las redes empresariales: los deberes fiduciários. Madrid: Marcial Pons, 2015.

AUBRY, Hélène. Un apport du droit communautaire au droit français des contrats: la notion d'attente legitime. Revue internationale de droit compare, vol. 57 n 3 , 2005, p. 627651.

AZEVEDO, Antonio Junqueira de. (Parecer) Diferenças de natureza e efeitos entre o negócio jurídico sob condição suspensiva e o negócio jurídico a termo inicial. A colaboração de terceiro para o inadimplemento de obrigação contratual. A doutrina doterceiro cúmplice. A eficácia externa das obrigações. In: AZEVEDO, Antonio Junqueira de. Estudos $e$ Pareceres de Direito Privado. São Paulo: Saraiva, 2004. p-208-225. 
. (Parecer) Os princípios do atual direito contratual e a desregulamentação do mercado. Direito de exclusividade nas relações contratuais de fornecimento. Função social do contrato e responsabilidade aquiliana do terceiro que contribui para inadimplemento contratual. In: AZEVEDO, Antonio Junqueira de. Estudos e Pareceres de Direito Privado. São Paulo: Saraiva, 2004. p-137-147.

Estudos e pareceres de direito privado. São Paulo: Saraiva, 2004.

- Negócio jurídico e declaração negocial- noções gerais e formação da declaração negocial. Tese. São Paulo, 1986.

Negócio Jurídico. Existência, validade e eficácia. $4^{\mathrm{a}}$ ed., São Paulo: Saraiva, 2010.

Novos estudos e pareceres de direito privado. São Paulo, SP: Editora Saraiva, 2009.

AZEVEDO, Luis André N. de Moura. O paradoxo da disciplina dos grupos de direito no Brasil sob uma perspectiva de direito e economia. In: ARAUJO, Danilo Borges dos Santos de; WARDE JR., Walfrido Jorge (Coord.). Os grupos de sociedades: organização e exercício da empresa. São Paulo: Saraiva, 2012, p. 177-193.

AZEVEDO, Paulo Furquim de: et alii. Origens, evolução e prática do franchising. In: ; SILVA, Vivian L. dos Santos (Org.) Teoria e prática do franchising. Estratégia e organização das redes de franquias. São Paulo: Atlas, 2012, p. 23-41.

; SILVA, André Gustavo Alves da; SILVA, Ricaro Young. Entre a autoridade e a autonomia: as gerações do franchising de alimentos, Trabalho apresentado ao IV Congresso Internacional de Economia e Gestão de Negócios Agroalimentares, 2003, p. 7.

Integração vertical e outros arranjos: polêmicas e esquecimento na defesa da concorrência. Anais do XXVI Encontro Nacional de Economia, Vitória: Anpec, 1998, p. 1327-1342, especialmente p. 1327-1329. 
BACHMANN, Reinhard. Trust, power and control in trans-organizational relations. In: Organization Studies, 2001, 22/2, p. 337-365.

BAKER, Scott; KRAWIEC, Kimberly. Incomplete contracts in a complete contract world. In: Bepress Legal Series Working Paper, n. 1294, 2006, p. 1-26.

BALLELL, Teresa Rodríguez de Las Heras. Aspectos jurídicos de las redes empresariales em internet. In: PERIS, Juan Ignacio Ruiz (Coord.). Nuevas Perspectivas Del Derecho De Redes Empresariales. Valencia: Tirant Lo Blanch, 2012, p. 393-435.

BARBA, Angelo. Redi di impresa e abuso di dipendenza econômica. In: CUFFARO, Vicenzo (a cura di). Contratto di rete di imprese. Milano: Giuffrè, 2016, p. 259-340.

BARROSO, Luiz Felizardo. A importância de um código de ética. In: Revista da Emerj, v.3, n. 9, 2000, p. 160-161.

BARTOLINI, Francesca. Il recesso nelle reti contrattuali. In: IAMICELI, Paola (Coord.). Le reti di imprese e i contratti di rete. Torino: Giappichelli, 2009. p.335-361.

BAUDRY, Bernard; CHASSAGNON, Virgile. The vertical network organization as a specific governance structure: what are the challenges for incomplete contracts theories and what are the theoretical implications for the boundaries of the (hub-) firm? In: Journal of Management \& Governance. v. 16 (2). 2012, p. 285-303.

BAULER, Anne; BOURIAU, Gaëlle. Les usages en droit commun des contrats, In: Mousseron, PiERre (coord.), Les usages en droit de l'entreprise, Paris: LexisNexis, 2010, p. 17-37.

BEALE, Hugy; DUGDALE, Tony. Contracts between Businessmen: Planning and the Use of Contractual Remedies. In: British Journal of Law and Society.Vol. 2. n. 1. 1975, p. 45-60.

BEEK, Nick van der. Long-term contracts and relational contracts. In: GEEST, Gerrit de Guest. Contract law and economics. Cheltenham: Edward Elgar, 2011. p. 281-313. 
BEHAR-TOUCHAIS, Martine; VIRASSAMY, Georges. Les contrats de la distribution, Paris: LGDJ, 1999.

BELLANTUONO, Giuseppe. I contratti incompleti nel diritto e nell'economia. Padova: CEDAM, 2000.

BELUSSI, Fiorenza. Creatività e routine nelle reti: business network, reti distrettuali, reti creative e catene globali del valore. In: LOPES, Antonio; MACARIO, Francesco; MASTROBERARDINO, Piero (Coord.). Reti di imprese, Scenari economici e giuridici. Torino: Giappichelli, 2007, p. 239-278.

BERGEL, Jean-Louis. Teoria Geral Do Direito. São Paulo: Martins Fontes, 2006.

BESIMO, Guido C.; HUBER, Charles. Virtuelle Fabrik Nordwestschweiz/Mittelland - ein Produktionsnetzwerk. In: HUBER, Charles: et alii. Kooperationsnetze der Wirtschaft. Einführung, Bausteine, Fallbeispiele, Zürich: VDF Hochschulverlag, 2005, p. 151-169.

BETTI, Emilio. Teoria Geral do Negócio Jurídico (tradução de Fernando de Miranda). Coimbra: Coimbra Editora, tomo I, 1969.

BEVILÁQUA, Clóvis. Código Civil dos Estados Unidos do Brasil Comentado. Rio de Janeiro: Editora Rio, $7^{\text {a }}$ Tiragem, 1943, v. II.

BOHNER, Reinhard. Asset-sharing in franchise networks: the obligation to pass on network benefits. In: AMSTUTZ, Marc; TEUBNER, Gunther (Coord.). Networks: Legal Issues of Multilateral Co-operation. Oxford: Hart Pub, 2009. p. 153-183.

BOISMAIN, Corinne. Les contrats relationnels. Marseille: Presses universitaires d'Aix-Marseille, 2005.

BOSI, Giacomo. Modelli di autoregolamentazione nelle reti di imprese. In: CAFAGGI, Fabrizio (Coord.). Reti di imprese tra regolazione e norme sociali: nuove sfide per diritto ed economia. Bologna: Il Mulino, 2004. p. 233-278. 
BOTTONI, Francesco. Incompletezza del contratto e riserva di determinazione convenzionale. Napoli: Scientifiche Italiane, 2013.

BOULAY, Jacques; KALIKA, Michel. Big brother is watching you! Le rôle des technologies de l'information dans la stratégie de contrôle des réseaux de points de vente franchises. In: Décisions Marketing, n. 45 (jan.-mar. 2007), p. 7-20.

; CHANUT, Odile. Les réseaux de franchise. Paris: La Découverte, 2010.

BOUT, Roger; DAVID, Ronan; BRUSCHI, Marc; LUBY, Monique; POILLOTPERUZZETTO, Sylvaine. Lamy Droit Économique: Concurrence, Distribution, Consommation. Paris: Éditions Lamy, 2016, n. 4020 (documento eletrônico).

BROS, Sarah. L'interdépendance contractuelle. Paris: Thèse Paris II, 2001.

BROWNSWORD, Roger. Contract law, co-operation, and good faith: the movement from static to dynamic market-individualism. In: DEAKIN, Simon; MICHIE, Jonathan. (Coord.) Contracts, co-operation, and competition: studies in economics, management, and law. Oxford: Oxford University Press, 2003. p. 255-284.

. Contracts with network effects: is the time now right? In: GRUNDMANN, Stefan; CAFAGGI, Fabrizio; VETTORI, Giuseppe (Coord.). The organizational contract: from exchange to long-term network cooperation in european contract law. Surrey: Ashgate, 2013. p. 137-162.

Network contracts revisited. In: AMSTUTZ, Marc; TEUBNER, Gunther (Coord.). Networks: Legal Issues of Multilateral Co-operation. Oxford: Hart Pub, 2009.p.31-52.

BULGARELLI, Waldírio. Atualidade dos Contratos Empresariais. Revista de Direito Mercantil, Industrial, Econômico e Financeiro, n. 84, outubro/dezembro 1991, p. 63-85. 
. Direito Empresarial Moderno. Rio de Janeiro: Forense, 1992.

. Waldírio. Normas jurídicas empresariais. 2a ed. São Paulo: Atlas, 2000.

BUONOCORE, Vicenzo. Diritto commerciale e diritto dell'impresa: per ricordare salli pescatore. Napoli: Scientifiche Italiane, 2008.

BUXBAUM, Richard M. Is "network" a legal concept? In: Journal of Institutional and Theoretical Economics, Vol. 149, No. 4 (Dec. 1993), p. 698-705.

CABRILLAC, Michel. Remarques sur la théorie génerale du contrat et les créations récentes de la pratique commerciale. In: Mélanges dédiés à Gabriel Marty. Toulouse: Université des sciences sociales de Toulouse, 1978, p. 235-254.

CAFAGGI, Fabrizio (a cura di). Il contratto di rete. Commentario. Bologna: Il Mulino, 2009.

. Contractual networks and contract theory: a research agenda for European

contract law. In: (Coord). Contractual networks, inter-firm cooperation and economic growth. Cheltenham Glos: Edward Elgar, 2011, p. 66-107.

- Contractual Networks and the Small Business Act: Towards European Principles? EUI Working Paper Law $n^{\circ}$ 2008/15, p.2, disponível em: www.dieresi.eu.

I doveri di cooperazione nei contratti: un'agenda di ricerca. In: IAMICELI, Paola (Coord.). Le reti di imprese e i contratti di rete. Torino: Giappichelli, 2009. p.363385.

. Il Contratto Di Rete: Commentario. Bologna: Il Mulino, 2009.

- Il governo della rete: modeli organizzativi del coordinamento interimprenditoriale. In: CAFAGGI, Fabrizio. (Coord.) Reti di imprese tra regolazione e norme sociali. Nuove sfide per diritto ed economia. Bologna: Il Mulino, 2004, p. 57-124. 
. Il nuovo contratto di rete: "Learning by doing"? In: I contratti, 12/2010, p. 1143-1154.

. Interrogativi deboli sui fondamenti del terzo contratto. In: GITTI, Gregorio; VILLA, Gianroberto (Coord.). Il terzo contrato. Bologna: Il Mulino, 2008. p.301-316.

- Organizational loyalties and models of firms: governance design and standard of duties. In: Theorethical Inquires in Law, v. 463, 2005, p. 463-526.

. Product Safety, Private Standard Setting and Information Networks, EUI Working Paper Law n. 2008/17, p. 24-25.

Reti contrattuali e contratti di rete: ripensando il futuro. In:

IAMICELI, Paola (Coord). Reti di imprese tra crescita e innovazione organizzativa. Riflessioni da uma ricerca sul campo. Bologna: Il Mulino, 2007, p. 413-448.

. Reti di imprese, spazi e silenzi regolativi. In: . (a cura di) Reti di imprese tra regolazione e norme sociali: nuove sfide per diritto ed economia. Bologna: Il Mulino, 2004. p.1-54.

. Reti di imprese tra regolazione e norme sociali. Nuove sfide per diritto ed economia. Bologna: Il Mulino, 2004, p. 57-124, p. 61.

. Reti di imprese: lungo il sentiero di una ricerca. In: ; IAMICELI, Paola. Reti di imprese tra crescita e innovazione organizzativa: riflessioni di una ricerca sui campo. Bologna: Il Mulino. 2007. p. 31-66.

; IAMICELI, Paola. Reti di imprese e modeli di governo interimprenditoriale: analisi comparativa e prospettive di approfondimento. In: . (a cura di). Reti di imprese tra crescita e innovazione organizzativa. Riflessioni da uma ricerca sul campo. Bologna: Il Mulino, 2007, p. 279-367. 
european networks? In ; VETTORI, Giuseppe (Coord.). The organizational contract: from exchange to long-term network cooperation in european contract law. Surrey: Ashgate, 2013. p.357-365.

CAMARDI, Carmelita. Dalle reti di impresa al contratto di rete nella recente prospettiva legislativa. In: I contratti, 2009, fascicolo 10, p. 928-934.

. Contratti di consumo e contratti tra imprese. Riflessioni sul'asimetria contratualle nei rapporti di scambio e nei rapporti "reticolare". In: Rivista critica del diritto privato, 2005, volume 23, fascicolo 4, p. 549-591.

Efficienza contrattuale e reti de imprese. In: LOPES, Antonio; MACARIO, Francesco; MASTROBERARDINO, Piero. (Coord.). Reti di imprese, scenari economici e giuridici. Torino: Giappichelli, 2007, p.331-361.

. I contratti di distribuzione come contratti di "rete". In: IAMICELI, Paola (Coord.). Le reti di imprese e i contratti di rete. Torino: Giappichelli, 2009. p.225-264.

CAMPBELL, David. Ian Macneil and the relational theory of contract. CDAMS Discussion Paper 04/1E, mar. 2004.

. The relational theory of contract: selected works of Ian Macneil. London:

Sweet \& Maxwell, 2001.

. COLLINS, Hugh. Discovering the implicit dimensions of contracts. In: ; WIGHTMAN, John. (Coord.). Implicit dimensions of contract: discrete, relational, and network contracts. Oxford: Hart Publishing, 2003. p. 25-49.

CANARIS, Claus-Wilhelm. Direitos fundamentais e direito privado. Coimbra: Almedina, 2003 (Tradução de Ingo Sarlet Wolfgang e Paulo Mota Pinto).

. Handeslrecht, München: C.H. Beck, 2006, 24 Auflage. 
Pensamento sistemático e conceito de sistema na ciência do direito. Lisboa: Fundação Calouste Gulbenkian, 2002.

CARMO, Lie Uema do. Contratos de construção de grandes obras. 2012. Tese de Doutorado. USP, São Paulo.

CARNELUTTI, Francesco. Teoria generale del diritto, Roma: Soc. Ed. Del Foro Italiano, 1951.

CASTELLS, Manuel. A sociedade em rede. São Paulo: Paz e Terra, $14^{\mathrm{a}}$ reimpressão, 2011, v. 1.

CASTILLA, Francisco González. La aplicación del principio de relatividad de los contratos a las redes de distribuición. In: RUIZ PERIS, Juan Ignacio. Hacia un derecho para las redes empresariales. Valencia: Tirant Lo Blanch, 2009. p.97-133.

CATRICALÀ, Antonio; GABRIELLI, Enrico. I Contratti Nella Concorrenza. Torino: UTET, 2011.

CERUTTI, Romeo; TBALZLI, Tina. Der Zahlungsverkehr der Banken (oder: es gibt den Netrzvertrag?). In: AMSTUTZ, Marc (Coord.). Die vernetze Wirtschaft. Netzverke als Rechtsproblem. Zürich: Shulthess, 2004, p. 87-106.

CHAMPAUD, Claude. La concession commerciale. Revue trimestrielle de droit commercial, T. XVI, 1963, p. 451-503.

CHASSAGNON, Virgile. The Network Firm as a Single Real Entity: Beyond the Aggregate of Distinct Legal Entities, disponível em: https://papers.ssrn.com/sol3/papers.cfm?abstract_id=1386962.

COASE, Ronald H. “The Nature of the Firm”. In: Economica, v. 4, n. 16, 1937, p. 386405.

The Firm, The Market and the Law. In: The firm, the market and 
the law. Chicago: The University of Chicago Press, 1990, p. 1-31.

. “The Problem of Social Cost". In: The Journal of Law \& Economics, v. 3, 1960, p. 1-44.

COCKBORNE, Jean-Eric de. "Franchising and the European Competition Law". In: JOERGES, Christian (org). Franchising and the law: theoretical and comparative approaches in Europe and the United States - Das Recht des Franchising: konzeptionelle, rechtsvergleichende und europarechtliche Analysen. Baden-Baden: Nomos Verlagsgesellschaft, 1991, p. 281-314.

COLLINS, Hugh. Introduction to networks as connected contracts. In: TEUBNER, Gunther. Networks as connected contracts (Tradução: Michelle Everson). Oxford: Hart Publishing, 2011.

- Introduction: the research agenda of implicit dimensions of contracts. In: CAMPBELL, David; ; WIGHTMAN, John. The implict dimension of contract: discrete, relational and network contracts. Oxford: Hart, 2003, p. 1-24.

. Regulating Contracts. Oxford: Oxford UP, 2002.

. The Weakest link: legal implications of the network architecture of supply chains. In: AMSTUTZ, Marc; TEUBNER, Gunther (Coord.). Networks: legal issues of multilateral co-operation. Oxford: Hart Pub, 2009. p.187-210.

COMPARATO, Fabio Konder. As cláusulas de não-concorrência nos shopping centers. In: Revista de Direito Mercantil. Industrial, Econômico e Financeiro, n. 97, 1995, p. 23-28. . Estado, empresa e função social. In: Revista dos Tribunais n. 732 (1996), p. $38-46$.

- Notas sobre parte e legitimação nos negócios jurídicos. In: Ensaios e pareceres de direito empresarial. Rio de Janeiro: Forense, 1978, p. 518. 
. Franquia e concessão de venda no Brasil: da consagração ao repúdio? In: . Ensaios e pareceres de direito empresarial. Rio de Janeiro: Forense, 1978, p. 372392.

Grupo societário fundado em controle contratual e abuso de poder do controlador (Parecer). In: Direito empresarial - estudos e pareceres. São Paulo: Saraiva, 1990, p. 270-291.

. Os grupos societários na nova lei de sociedade por ações. In:

Ensaios e pareceres de direito empresarial. Rio de Janeiro: Forense, 1978, p. 193-219.

Parecer complementar. In: - Direito empresarial - estudos e pareceres. São Paulo: Saraiva, 1990, p. 283-291.

- Restrições à circulação de ações em companhia fechada: nova et vetera.In: Novos ensaios e pareceres de direito empresarial. Rio de Janeiro: Forense, 1981. p. 32-51. ; SALOMÃO FILHO, Calixto. O poder de controle na sociedade anônima. Rio De Janeiro: Editora Forense, 2008.

COOTER, Robert; ULEN, Thomas. Direito e economia. 5 ${ }^{\mathrm{a}}$ ed. Porto Alegre: Bookman, 2010.

COSTA, Carlos Celso Orcesi da. Controle externo nas companhias. Revista de direito mercantil, industrial, econômico e financeiro, São Paulo, n. 44, ano XX, p.70-75, outubro/dezembro de 1981.

COSTA, Philomeno J. da. Resenha à obra Grupos de Sociedades y acionistas minoritários. In: Revista de direito mercantil, industrial, econômico e financeiro, n. 78, 1990, p. 81. 
COUTO E SILVA, Clóvis Veríssimo do. A obrigação como processo. Rio de Janeiro: FGV, 2006.

A teoria da base do negócio jurídico no direito brasileiro. In: Revista dos Tribunais, vol. 655, 1990, p. 7-11.

CRAPANZANO, Guido A. M. Mito e realtà del controllo contrattuale di fatto delle società. In: Analisi Giuridica dell'Economia, 2/2011, p. 361-384.

CREA, Camilla. Contractual business networks: Interpretation criteria and axiological perspective. In: JUNG, Stefanie; KREBS, Peter; TEUBNER, Gunther (Coord.). Business networks reloaded. Baden-Baden: Nomos, 2015, p. 354-380.

Reti contrattuali e organizzazione dell' attività d' impresa. Napoli: Edizioni Scientifiche Italiane, 2008.

CROUCH, Colin. The place of networks in governance theory. In: CAGAFFI, Fabrizio. (a cura di) Corporate governance, networks e innovazione. Trento: Cedam, 2005. p. 1-23.

CUNHA, Miguel Maria Tavares Festas Gorjão-Henriques da. Da restrição da concorrência na comunidade europeia: a franquia de distribuição. Coimbra: Almedina, 1998.

DEAKIN, Simon; LANE, Christel; WILKINSON, Frank. "Contract Law, Trust Relations, and Incentives for Co-operation: A Comparative Study”. In: DEAKIN, Simon; MICHIE, Jonathan. (Coord.) Contracts, co-operation, and competition: studies in economics, management, and law. Oxford; New York: Oxford University Press, 1997.

The Return of the Guild? Network relations in historical perspective. In: AMSTUTZ, Marc; TEUBNER, Gunther. Networks: legal issues of multilateral cooperation. Oxford: Hart Pub, 2009. p. 53-73.

DINIZ, Gustavo Saad. Dependência econômica nos acordos verticais. In: Revista de 
Direito Privado, vol. 59, 2014, p. 91-120, documento eletrônico.

DNES, Antony. Franchise contracts. In: GEEST, Gerrit de Guest. Contract law and economics. Cheltenham: Edward Elgar, 2011. p.384-397.

DOLŽAN, Judita. Außen- und Binnendurchgriff im Vertragsnetz. Berlin: De Gruyter, 2015.

DRUEY, Jean Nicolas. The path to the law - the difficult legal access of networks. In: AMSTUTZ, Marc; TEUBNER, Gunther. Networks: legal issues of multilateral cooperation. Oxford: Hart Pub, 2009. p.87-99.

DUBISSON, Michel. Les groupements d'entreprises pour les marchés internationaux. Paris: F.E.D.U.C.I., 1979.

EISENBERG, Melvin Aron. "Why there is no Law of Relational Contracts". Northwestern University Law Review, vol. 94 (2000), p. 805-821.

. The limits of cognition and the limits of contract. In: Berkeley Law Scholarshop Repository, v. 47, 1995, p. 211-259.

ENEI, José Virgílio Lopes Enei. Contratos coligados. In: Revista de direito mercantil, industrial, comercial e econômico, v. 132, 2003, p. 112-128.

ESSER, John. Institutionalizing industry: the changing forms of contract. In: Law \& Social Inquiry, v. 21, n. 3, 1996, p. 593-629.

FAUCEGLIA, Giuseppe. Il franchising: profili sistematici e contrattuali, Milano, Giuffrè, 1988.

FEMIA, Pasquale. Nomenclatura del contratto o instituzione del contrarre? Per una teoria giuridica della contrattazione. In: GITTI, Gregorio; VILLA, Gianroberto. (Coord.) Il terzo contrato. Bologna: Il Mulino, 2008. p.264-299. 
FERNANDES, Marcelo Cama Proença. Contratos: eficácia e relatividade nas coligações contratuais, São Paulo: Saraiva, 2014.

FERRIER, Didier. Droit de la distribution. Paris: Litec, 2009. La considération juridique du réseau. In: Mélanges Christian Mouly, (publié par le Centre du droit de l'entreprise). Paris: Litec, 1998. p. 95-113.

FERRIER, Nicolas; SAUTONIE-LAGUIONIE, Laura. La distribution parallèle à l'épreuve de l'opposabilité du réseau. In: Revue Trimestrielle de Droit Civil, n. 2, 2011, p. 225-247.

FERRO-LUZZI, Paolo. I contratti associativi. Milano: Giuffrè, 1976.

FICI, Antonio, Il franchising. In: SIRENA, Pietro (a cura di). I contratti di collaborazione, Torino: UTET, 2011, p. 955-1080.

Il contratto incompleto. Torino: Giappichelli, 2005.

FLICK, Maurizio. Il contratto nele "reti di imprese": problemi e prospective. In: Rivista di diritto privato, 2008, volume 13, fascicolo 2, p. 339-372.

FLOHR, Eckhard. Franchise-Vertrag, 4ª ed., München: C.H. Beck, 2010.

FORGIONI, Paula Andrea. A evolução do direito comercial brasileiro: da mercancia ao mercado. São Paulo: RT, 2009.

. Contrato de distribuição. São Paulo: RT, 2014, $3^{\mathrm{a}}$ ed.

. Contratos empresariais. Teoria geral e aplicação, São Paulo: RT, 2015.

FRADA, Manuel Antônio de Castro Portugal Carneiro da. Teoria da confiança e responsabilidade civil. Coimbra: Almedina, 2007 (reimpressão). 
. Contrato e deveres de proteção. Coimbra: Almedina, 1994.

FRANÇA, Erasmo Valladão Azevedo e Novaes. Conflito de interesses nas assembleias de S.A (e outros escritos sobre conflitos de interesses). São Paulo: Malheiros, 2014, $2^{\mathrm{a}}$ ed.

; ADAMEK, Marcelo Vieira Von. "Affectio Societatis": um conceito jurídico superado no moderno direito societário pelo conceito de fim social". In: (Coord.). Temas de direito societário, falimentar e teoria da empresa. São Paulo: Malheiros, 2009, p. 27-68.

FRANCO, Vera Helena de Mello. Direito Empresarial I, São Paulo: RT, 2009, $3^{\text {a }}$ ed.

GATSI, Jean. Le contrat cadre. Paris: L.G.D.J., 1996.

GEIS, Geoge S. Business Outsourcing and the Agency Cost Problem. Notre Dame Law Review, n. 82, 2013, p. 955-1003.

GENTILI, Aurelio. Una prospettiva analitica sulle reti di imprese e contratti di rete. In: Obbligazioni e contratti, 2010, volume 6, fascicolo 2, p.87-90.

GIESLER, Jan Patrick; JÜRGEN, Nauschütt. Franchiserecht, 2a ed. Köln: Luchterhand/Wolters Kluwer, 2007.

GILETTE, Clayton. Contractual networks, contract design, and contract interpretation: the case of credit cards. In: GRUNDMANN, Stefan; CAFAGGI, Fabrizio; VETTORI, Giuseppe (Coord.). The organizational contract: from exchange to long-term network cooperation in european contract law. Surrey: Ashgate, 2013. p. 77-95.

GILSON, Ronald J.; SABEL, Charles F.; SCOTT, Robert E. Braiding: The Interaction of Formal and Informal Contracting in Theory, Practice and Doctrine. In: Columbia law and economics working paper, $\mathrm{n}^{\circ} .367$ (2010), disponível em http://ssrn.com/abstract=1535575. ; SABEL, Charles F.; SCOTT, Contracting for Innovation: Vertical 
Disintegration and Inter-firm Collaboration. In: Columbia law and economics working paper, $\mathrm{n}^{\circ} .340$ (2009), disponível em http://ssrn.com/abstract=1289428

GITTI, Gregório; VILLA, Gianroberto. Il terzo contratto. Il Mulino, Bologna, 2008.

GOBBATO, Marco. Franchising e innovazione: spunti dalla nuova disciplina dell'affiliazione commerciale. In: CAGAFFI, Fabrizio. (a cura di) Corporate governance, networks e innovazione. Trento: Cedam, 2005. p. 161-214.

- Long-term relationships, networks and exchange of knowledge in production and distribution contracts. In: GRUNDMANN, Stefan; CAFAGGI, Fabrizio; VETTORI, Giuseppe (Coord.). The organizational contract: from exchange to long-term network cooperation in european contract law. Surrey: Ashgate, 2013. p.231-265.

GOLDBERG, Daniel. Poder de compra e política antitruste, São Paulo: Ed. Singular, 2006.

GOLOBARDES, Mireia Artigot i; POMAR, Fernando Gómez. Dissecting long-term contracts: a law and economic approach. In: GRUNDMANN, Stefan; CAFAGGI, Fabrizio; VETTORI, Giuseppe (Coord.). The organizational contract: from exchange to long-term network cooperation in european contract law. Surrey: Ashgate, 2013. p.41-75.

GOMES, Orlando. Contratos. Rio de Janeiro: Forense, 26ª ed., 2009.

GRANDORI, Anna; SODA, Giuseppe. Interfirm networks: antecedents, mechanisms and forms. In: Organization Studies, vol. 16, 1995, p. 183-214.

GRANIERI, Massimiliano. Brevi note sulle reti di imprese tra concorrenzialità e concorrenza. In: LOPES, Antonio; MACARIO, Francesco; MASTROBERARDINO, Piero (Coord.). Reti di imprese, scenari economici e giuridici. Torino: Giappichelli, 2007, p. 375395.

Il tempo e il contratto. Itinerário storico-comparativo sui contratti di durata.

Milano: Giuffrè, 2007. 
GRANOVETTER, Mark Economic Action and Social Structure: The problem of embeddedness. American Journal of Sociology, vol. 91, nº 3, 1995, p. 481-510.

GRAU, Eros Roberto. Ensaio e discurso sobre a intrepretação/aplicação do direito. $3^{\text {a }}$ ed. São Paulo: Malheiros, 2005.

. Um novo paradigma dos contratos? In: Revista Trimestral de Direito Civil, n. 5, jan./mar/2001, p. 73-82.

; FORGIONI, Paula A. Ainda um novo paradigma dos contratos? In: . O Estado, a Empresa e o Contrato. São Paulo: Malheiros, 2005.

GRIMALDI, Cyril; MÉRESSE, Serge; ZAKHAROVA-RENAUD, Olga. Droit de la franchise. Paris: Litec, 2010.

GRUNDMANN, Stefan. "Vertragsnetz um wegfall der Gesschäftgrundlage". In: ADERHOLD, Lutz (Org.). Festschrift für Harm Peter Westermann zum 70. Geburtstag. Köln, 2008, p. 227-244.

Contractual networks in german private law. In: CAFAGGI, Fabrizio (Coord.). Contractual networks, inter-firm cooperation and economic growth. Cheltenham Glos:Edward Elgar, 2011, p. 111-162.

. Qual a unidade do direito privado? De uma concepção formal a uma concepção material do direito privado. In: : et alii (Coord.). Direito privado, constituição e fronteiras. São Paulo: RT, $2^{\mathrm{a}}$ ed., 2013, p. 234-261.

; CAFAGGI, Fabrizio; VETTORI, Giuseppe. The contractual basis of longterm organization - the overall architecture. In:

(Coord.). The organizational contract: from exchange to long-term network cooperation in european contract law. Surrey: Ashgate, 2013. p.3-38.

; MÖSLEIN, Florian; RIESENHUBER, Karl. Contract governance: 
dimensions in Law and interdisciplinary research. In ; MÖSLEIN, Florian; RIESENHUBER, Karl (Coord.). Contract governance: dimensions in Law and interdisciplinary research, Oxford: Oxford University Press, 2015, p. 3-57.

GUERINONI, Ezio. Incompletezza e completamento del contratto. Milano: Giuffrè, 2007.

GUIDUGLI, João Henrique. Controle externo contratual. $O$ desenvolvimento da empresa e os grupos de contratos sob o direito societário. São Paulo: Quartier Latin, 2006.

GÜTTLER, Nina Marie. Der Binnendurchgriff im Franchisesystem. In: Jahrbuch Junger Zivilrechtswissenchaftler 2015 (Netzwerke im Privatrecht). Berlim: Richard Boorberg Verlag, 2016, p. 69-91.

GUYENOT, Jean. La franchise commerciale. In: Revue Trimestreille de Droit Commercial, n. 2, 1973, p. 161-175.

Les contrats de concession commerciale. Droit français e communautaire de la concurrence. Paris: Sirey, 1968.

Les conventions d 'exclusivité de vente. In: Revue Trimestrielle de Droit Commercial, n. 3, 1963, p. 513-537.

. Les ventes avec clauses d'exclusivite et les groupements commerciaux de concessionnaires. In: Gazette du Palais (recueil bimestrial), 31.8.1972, p. 481-490.

HABERMAS, Jürgen. Paradigms of law. In: Cardozo Law Review, v. 17, (1995 1996), p. 771-784.

HART, Oliver; MOORE, John. Agreeing not to argue later: contracts that rule out but do not ruin it. In: Discussion paper n. 465, 2004. p. 1-56.

HEERMANN, Peter. Drittfinanzierte erwerbsgeschäfte. Tubingen: Mohr Siebeck, 1998. 
The status of multilateral synallagmas in the law of connected contracts. In: AMSTUTZ, Marc; TEUBNER, Gunther (Coord.). Networks: Legal issues of multilateral co-operation. Oxford: Hart Pub, 2009. p.103-118.

HELDT, Cordula. Baukooperation und Franchising als multilatelare Sondervenbindung, Baden-Baden: Nomos, 2010.

. Internal relations and semi-spontaneous order: the case of franchising and construction contracts. In: AMSTUTZ, Marc; TEUBNER, Gunther (Coord.). Networks: Legal Issues of Multilateral Co-operation. Oxford: Hart Pub, 2009. p.137-152.

HELPER, Susan; MACDUFFIE, John Paul; SABEL, Charles. Pragmatic collaborations: advancing knowledge while controlling opportunism. In: Industrial and Corporate Change, v. 9, 2000, p. 443-488.

HENNEMANN, Moritz. Informationspflichten in Vertragsnetzwerken. Grundlagen, Reichweite und Ausgestaltung. In: Jahrbuch Junger Zivilrechtswissenchaftler 2010 (Vertrauen und Kontrollle im Privatrecht). Berlim: Richard Boorberg Verlag, 2011, p. 285301.

HESPANHA, António Manuel. A cultura jurídica europeia: síntese de um milénio. Coimbra: Almedina, 2012.

HILLMAN, Allan. Third-party beneficiaries in franchising: "between the conception and the creation... falls the shadow". In: Franchise Law Journal, v. 85, 2011-2012, p. 85101.

HIRATA, Alessandro. Relações contratuais fáticas: faktische Vertragsverhaltnisse. São Paulo: USP, 2011, 153 p. Tese apresentada para concurso para professor titular junto ao departamento de direito civil da faculdade de direito da Universidade de São Paulo, São Paulo, 2011.

HIRONAKA, Giselda Maria Fernandes Novaes. O sinalagma contratual. A chamada 
causa dos contratos. Relações contratuais de fato. In: CAMPOS. Alyson Rodrigo Correia; CASTRO JÚNIOR, Torquato da Silva. (Org.). Dos contratos. 1 ed. Recife: Nossa Livraria, 2012, v. 1, p. 19-49.

HOFF, Debora Nayar; BRUCH, Kelly Lissandra; LAGO, Adriana. CAMARGO, Daniele Christiane Hoff Marinho de. Efeitos sistêmicos em relações contratuais ocasionados pelo oportunismo: um estudo do comércio da soja entre China e Brasil em 2004. In: Revista de Administração da UNIMEP, v. 7, n.1, 2009, p. 138-162.

HÜFFER, Uwe. Die Haftung gegenüber dem ersten Auftraggeber im mehrgliedrigen Zahlungsverkehr. In: Zeitschrift für das gesamte Handels- und Wirtschaftsrecht, vol. 151 (1987), p. 93-117.

HUNE, Michael. Netzwerkverträge in Der Transportwirtschaft: Wirtschaftliche Und Rechtliche Dimensionen Einer Modernen Vertragsverbindung Zwischen Wettbewerb Und Kooperation. Berlin: Wiss. Verl., 2010.

IAMICELI, Paola. Dalle reti di imprese al contratto di rete: um percorso (in)compiuto. In: (a cura di) Le reti di imprese e i contratti di rete, Torino: Giappichelli, 2009, p. 1-43.

IAMICELI, Paola. Il contratto di rete tra percorsi di crescita e prospettive di finanziamento. In: I contratti 2009, fasciolo 10, p. 942-951.

IAMICELI, Paola. Il coordinamento della filiera produtiva: tra collegamento negoziale e contratti di rete. In: CAFAGGI, Fabrizio; ( a cura di) MOSCO, Gian Domenico. Il contratto di rete per la crescita delle imprese. Milano: Giuffrè, 2012. p.315-345.

. Le reti di imprese: modeli contrattuali di coordinamento. In: CAFAGGI, Fabrizio (a cura di). Reti di imprese tra regolazione e norme sociali. Nuove sfide per diritto ed economia. Bologna: Il Mulino, 2004, p. 125-175.

IRTI, Natalino. L'ordine giuridico del mercato. Roma: Laterza, 2003. 
JAEGER, Pier Giusto. L'interesse sociale, Milano: Giuiffrè, 1972 (reimpressão).

JENNEJOHN, Matthew C. Collaboration, innovation and contract design. In: Working paper, v. 319, 2007, p. 1-68. Disponível em: http://ssrn.com/abstract=1014420.

Governing innovative collaboration: a new theory of contract. 2006. Disponível em: http://ssrn.com/abstract=937127.

JOHANSON, Jan; MATTSSON, Lars-Gunnar. Interorganizational relations in industrial systems: a network approach compared with the transaction-cost approach. In: International Studies of Management \& Organization, 1987, Vol. 17, n. 1, p. 34-48.

JOLLS, Chirstine; SUNSTEIN, Cass; THALER, Richard. A behavioral approach to law and economics. In: Chicago Law and Economics Working Paper, v. 55, 1998 p. 2-99.

KATAOKA, Eduardo Takemi. A coligação contratual. Rio de Janeiro: Lúmen Júris, 2008.

KIRCHNER, Christian. Symbiotic arrangements as a challenge to antitrust. In: Journal of Institutional and Theoretical Economics, Vol. 152, No. 1 (March 1996), p. 226243.

- Unternehmensorganisation und vertragsnetz: überlegungen $\mathrm{zu}$ den rechtlichen bedingungen bei der institutionenwahl zwischen unternehmensorganisation und vertragsnetz. In: OTT, Claus; SCHÄFER, HANS-BERND. Ökonomische analyse des unternehmensrechts. Heidelberg: Physica Verlag, 1993, p. 196-215.

KONDER, Carlos Nelson. Causa do contrato x função social do contrato: Estudo comparativo sobre o controle da autonomia negocial, Rio de Janeiro: RTDC - Revista Trimestral de Direito Civil, ano 11, vol. 43, jul/set 2010, p. 33-75.

. Contratos conexos: grupos de contratos, redes contratuais e contratos coligados. Rio de Janeiro: Renovar, 2006. 
KREBS, Peter. Sonderverbindung und außerdeliktische Schutzpflichten. Munich: Beck, 2000.

; AEDTNER, Katja; SCHULTES, Marion. Company networks reloaded putting a general functional approach to defining complex problems to the test. In: JUNG, Stefane; ; TEUBNER, Gunther (Coord.). Business networks reloaded. BadenBaden: Nomos, 2015, p. 41-73.

; JUNG, Stefane. Governance structures in business networks. In:

.; TEUBNER, Gunther (Coord.). Business networks reloaded. Baden-Baden: Nomos, 2015, p. 118-170.

KRISHNAN, Ranjani; MILLER, Fabienne; SEDATOLE, Karen. Collaborative contracting in inter-firm relationships. In: Contemporary accounting research conference, Kingston, Ontario, November 5-6, 2010. Disponível em: SSRN: http://ssrn.com/abstract=1004126.

KULMS, Rainer. Schuldrechtliche organisationsvertrage in der unternehmenskooperation. Baden-Baden: Nomos Verlagsgesellschaft, 2000.

KUYVEN, Luiz Fernando Martins. Cooperação como princípio diretor dos contratos: a lição dos acordos de acionistas. In: (Coord.). Temas essenciais de direito empresarial: estudos em homenagem a Modesto Carvalhosa. São Paulo: Saraiva, 2012. p.764-789.

LAFONTAINE, Francine; SLADE, Margaret E. Transaction costs economics and vertical market restrictions - Evidence. In: The antitrust bulletin, Vol. 55, nº. 3, 2010, p. 587 611.

LAMY FILHO, Alfredo; PEDREIRA, José Luiz BULHÕES. Direito das companhias, Rio de Janeiro: Forense, 2009, vol. 1.

LANGE, Knut Werner. Das Recht der Netzwerke: Moderne Formen der Zusammenarbeit in Produktion und Vertrieb. Heidelberg: Verlag Recht und Wirtschaft, 
1998.

LANGLOIS, Richard N.; ROBERTSON, Paulo L. Firms, markets and economic change - A dynamic theory of business institutions. New York: Routledge, 1995.

Transaction-cost Economics in Real Time. In: Industrial and corporate change, vol. I, n. 1, 1992, p. 99-127.

LARENZ, Karl; WOLF, Manfred. Allgemeiner teil des bürgerlichen rechts. München: Beck, 2004.

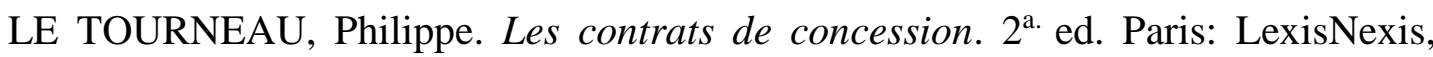
2010.

. Les contrats de franchise. $2^{\text {a. }}$ ed. Paris: LexisNexis, 2007.

LEÃES, Luis Gastão Paes de Barros. Aspectos contratuais do processo modular de produção. In: Pareceres. São Paulo: Singular, 2004, p. 699-704, v. I.

Pareceres, São Paulo: Singular, 2004, v. I, p. 42-43.

LECOURT, Arnaud; BONDIL, Frédéric. Réseaux de distribution. Rueil-Malmaison: Lamy, 2013.

LEITÃO MARQUES, Maria Manuel. Du commerce international aux échanges intragroupes et entre membres d'associations decoopération. L'entreprise poly-locale et les réseaux. In: Revue Internationale de Droit Economique, 3-4, 2003, p. 411-441.

LELOUP, Jean-Marie. La franchise: droit et pratique, Paris: Dalloz, 3a ed., 2000. Le partage du marché par les réseaux de vente et les réseaux de distribution. In: YVES GUYON, JEANNE BOUCOURECHLIEV, ALFRED JAUFFRET (Coord.). Dix ans de droit d'entreprise, Paris: Litec, 1978, p. 933-956, p. 955). 
LEMLEY, Mark A; MCGOWAN, David. Legal implications of network economic effects. In: California Law Review, vol. 86, 1998, p. 479-611. Disponível em: http://scholarship.law.berkeley.edu/californialawreview/vol86/iss3/7, acesso em 10.02.2014.

LEONARDO, Rodrigo Xavier. Os contratos coligados, os contratos conexos e as redes contratuais. In: MODESTO CARVALHOSA (Coord.). Tratado de direito empresarial, São Paulo: RT, 2016, vol. IV, p. 456-496.

. Redes contratuais no mercado habitacional. São Paulo: RT, 2003.

LEQUETTE, Suzanne. Le contrat-coopération: contribution à la théorie générale du contrat. Paris: Economica, 2012.

LIMA MARQUES, Claudia. Contratos no código de defesa do consumidor. São Paulo: RT, 2002, $4^{\mathrm{a}}$ ed.

; MIRAGEM, Bruno (nota de atualização). PONTES DE MIRANDA, Francisco Cavalcanti. Tratado de Direito Privado. tomo XLIV, São Paulo: Revista dos Tribunais, 2013.

LIPARI, Nicolò. Le categorie del diritto civile. Milano: Giuffrè, 2013.

LEWELLYN, Karl N. What price contract? An essay in perspective. Yale law journal, v. 40,1931 , p. $704-751$.

LOPES, Antonio; MACARIO, Francesco; MASTROBERARDINO, Piero. Introduzione. In: (a cura di) Reti di imprese, scenari economici e giuridici. Torino: Giappichelli, 2007, p. XII- XXXIV.

LORENZETTI, Ricardo Luis. Fundamentos do Direito Privado. São Paulo: Editora Revista dos Tribunais, 1998.

Tratado de los contratos. Buenos Aires: Rubinzal - Culzoni Editores, 2004, 
tomo I.

. Redes Contractuales: Conceptualizaciòn juridica, relaciones internas de colaboracion, efectos frente a terceiros. In: Revista da Faculdade de Direito da UFRGS, n. 16, 1999, p. 161-202.

LUBER, Michael. Der mehrseitige Austauschvertrag. Eine materiellrechtliche und zivilprozessuale Untersuchung. München: Herbert Utz Verlag, 2004.

LUCENA, José Waldecy. Das sociedades limitadas. Rio de Janeiro: Renovar, 2005, $6^{\mathrm{a}} \mathrm{ed}$

LUHMANN, Niklas. Confianza. México: Universidade Iberoamerica e Anthropos, 1996

LUPION, Ricardo. Boa-fé objetiva nos contratos empresariais: contornos dogmáticos dos deveres de conduta. Porto Alegre: Livraria do Advogado, 2011.

LYONS, Bruce; MEHTA, Judith. Private sector business contracts: the text between the lines. In: DEAKIN, Simon; MICHIE, Jonatham (Coord.). Contracts, co-operation, and competition: studies in economics, management, and law. Oxford: Oxford University Press, 1997, p. 43-66.

MACARIO, Francesco. Adeguamento e rinegoziazione nei contratti a lungo termine. Napoli: Jovene Editore, 1996.

. Reti di imprese, "contratto di rete" e individualizazione delle tutele. Appunti per uma riflessione metodológica. In: IAMICELI, Paola. (a cura di). Le reti di imprese e $i$ contratti di rete, Torino: Giappichelli, 2009, p. 273-294.

; SCOGNIAMIGLIO, Claudio. Reti di imprese e contratti di rete: spunti per um dibattito. In: I contratti, 2009, fascicolo 10, p.915-927.

MACAULAY, Stewart. Non-contractual relations in business: a preliminar study. 
American Sociological Review, vol. 28, nº 1, 1963, p. 55-67.

. The real and the paper deal: empirical pictures of relationships, complexity and the urge for transparent simple rules, The Modern Law Review, 2003, v. 66, n. 1, p. 4479.

The real and the paper deal: empirical pictures of relationships, complexity and the urge for transparent simple rules. In: CAMPBELL, David; COLLINS, Hugh; WIGHTMAN, John. The implict dimension of contract: discrete, relational and network contracts. Oxford: Hart, 2003, p. 51-102.

MACEDO JR., Ronaldo Porto. Contratos Relacionais e Defesa do Consumidor. $2^{\mathrm{a}}$ ed., São Paulo: RT, 2007.

. Ensaios de teoria do direito. São Paulo: Saraiva, 2013.

Interpretação da boa-fé nos contratos brasileiros: os princípios jurídicos em uma abordagem relacional (contra a euforia principiológica). In: Direito e interpretação: racionalidades e instituições. ; BARBIERI, Catarina Helena Cortada (Orgs.). São Paulo: Saraiva, 2011.

MACNEIL, Ian R. Bureaucracy Liberalism and Community--American Style, Northwestern University Law Review 79, n. 5 e 6, 1985, p. 900-948.

. Contracts: adjustment of long-term economic relations under classical, neoclassical, and relational contract law. In: Northwestern University Law Review, v. 72, n. 6, 1978, p. 854-905;

O novo contrato social. (Tradução de Alvamar de Campos Andrade Lamparelli). Rio de Janeiro: Elsevier, 2009.

The many futures of contracts, Southern California Law Review, v. 47, 1974, p. 691-816. 
. Values in contract: internal and external. In: Northwestern University Law Review, v. 78, n. 2, 1983, 340-418.

MALAURIE-VIGNAL, Marie. Droit de la distribution. Paris: Sirei, 2015, $3^{\text {a }}$ ed.

MALZER, Matthias. Vertragsverbünde und vertragssysteme: ein beitragzur systematischen einordnung mehrpoliger rechtsbeziehungen. Baden-Baden: Nomos, 2013.

MANCINI, Daniela. Il sistema informativo e di controllo relazionale per il governo della rete di relazioni collaborative d'azienda. Milano: Giuffrè, 2010.

MARINO, Francisco Paulo de Crescenzo. Contratos coligados no direito brasileiro. São Paulo: Saraiva, 2009.

MARKESINIS, Sir Basil; HANNES UNBERATH E ANGUS JOHNSTON, The german law of contract. A comparative treatise. Oxford: Hart Publishing, 2a ed., 2006.

MARKOVITS, Daniel. Contract and collaboration. Yale Law Journal, vol. 113 (2004), p. 1417-1518.

MARTEL, David. Le rapport d'obligation dans une communauté de personnes. Paris: IRJS Éd., 2012.

MARTINEK, Michael. Franchising: Grundlagen der zivil- und wettbewerbsrechtlichen Behandlung der vertraglichen Gruppenkooperation beim Absatz von Waren und Dienstleistungen. Heidelberg: von Decker, 1987.

. Moderne Vertragstypen. München: Beck, 1992, v. II.

. Moderne vertragstypen. München: Beck, 1993, v. III.

. Networks of contracts and competition law. In: GRUNDMANN, Stefan; CAFAGGI, Fabrizio; VETTORI, Giuseppe (Coord.). The organizational contract: from exchange to long-term network cooperation in european contract law. Surrey: Ashgate, 
2013. p.163-178.

. Recensão a MATHIAS ROHE. Netzverträge - Rechtsprobleme komplexer Vertragsverbindungen. In: Neue Juristische Wochenschrift (NJW) 2000, p. 1397.

: et al. Formularsammlung Vertriebsrecht, München: C.H. Beck, 2013.

: et al. Handbuch des Vertriebsrechts, München: C.H. Beck, 2016.

. SEMLER, Franz-Jörg; HABERMEIER, Stefan. (Coord.) Handbuch des Vertriebsrechts, 3a ed. München: Verlag C.H. Beck, 2010.

MARTINÉZ-PUJALTE, Carmen Cerdá. Coordinación empresarial em las redes versus control antitrust: análisis del nuevo Regulamento CE 330/2010 em clave de red. In: RUIZ PERIS, Juan Ignacio. Nuevas perspectivas del derecho de redes empresariales. Valencia: Tirant Lo Blanch, 2012. p.531-546.

MARTINS COSTA, Judith Hofmeister. Princípio da confiança legítima e princípio da boa-fé objetiva. Termo de compromisso de cessação (TCC) ajustado com o Cade. Critérios da interpretação contratual: os "sistemas de referência extracontratuais" ("circunstâncias do caso") e sua função no quadro semântico da conduta devida. Princípio da unidade ou coerência hermenêutica e "usos do tráfego". Adimplemento contratual (Parecer). RT nº 852, 2006, p. 87-126.

A boa-fé no direito privado: critérios para a sua aplicação. São Paulo: Marcial Pons, 2016.

A teoria da causa em perspectiva comparativista: a causa no sistema civil francês e no sistema civil brasileiro, Porto Alegre: AJURIS - Revista da Associação dos Juízes do Rio Grande do Sul, n. 45, ano XVI, março 1989, p. 213-243.

Contrato de de seguro. Suicídio do segurado. Art. 798, Código Civil. Interpretação. Diretrizes e princípios do Código Civil. Proteção ao consumidor (Parecer). In: Revista Brasileira de Direito Civil, n. Vol. 1, jul./set. 2014, p. 223-270. 
Reflexões sobre o princípio da função social dos contratos. In: CUNHA, Alexandre dos Santos. (Coord). O direito da empresa e das obrigações e o novo Código Civil brasileiro. São Paulo: Quartier Latin, 2006. p. 218-248.

MARX, Valérie. La dimension collective des réseaux de distribution. Paris: Atelier national de reproduction des thèses, 2008.

La dimension collective des réseaux de distribution. Paris: Atelier national de reproduction des thèses, 2008.

MAUGERI, Maria Rosaria. Abuso di dipendenza e affiliazione commerciale: ambito de applicazione, contenuto del contrato, caratteri del rimedio e tutela della rete. In: LOPES, Antonio; MACARIO, Francesco; MASTROBERARDINO, Piero. (a cura di). Reti di imprese, scenari economici e giuridici. Torino: Giappichelli, 2007, p.363-374.

. Reti contrattuali e abuso di dipendenza economica: alla ricerca di nuove discipline? In: IAMICELI, Paola. Le reti di imprese e i contratti di rete. Torino: Giappichelli, 2009. p.294-328.

. Reti di impresa e contratto di rete. In: I contratti, 2009, fascicolo 10, p. 957961.

. Reti di imprese, contratto di rete e reti contrattuale. In: Obbligazioni e contratti, 2009, volume 5, fascicolo 12, p. 951-962.

MELLO FRANCO, Vera Helena de. Os contratos empresariais e seu tratamento após o advento do código civil de 2002. In: Revista de direito mercantil, industrial, econômico e financeiro, n. 151/152, jan./dez/2009, p. 22-46.

MELLO, Marcos Bernades de. Teoria do fato jurídico: Plano da eficácia, $1^{\text {a }}$ parte, São Paulo: Saraiva, 2003.

MELO, Claudineu de. Contrato de distribuição. São Paulo: Saraiva, 1987. 
MÉNARD, Claude. Hybrid Organisation of Production and Distribution. In: Revista de análisis económico, vol. 21, $\mathrm{n}^{\mathrm{o}}$ 2, 2006, p. 25-41, disponível em http://ssrn.com/abstract=1239162.

The Economics of Hybrid Organizations. In: Journal of institutional and theoretical. economics, $\mathrm{n}^{\circ} 160,2004$, p. 345-375.

MENDES, Gimar Ferreira. Direitos fundamentais: eficácia das garantias constitucionais nas relações privadas. In: GRUNDMANN, Stefan: et alii (Coord.). Direito privado, constituição e fronteiras. São Paulo: RT, $2^{\mathrm{a}}$ ed., 2013, p. 31-55.

MENDES, Rodrigo O. Bróglia. A empresa em rede: e empresa virtual como mote para reflexão no direito comercial. In: Revista do Advogado, Ano XXXI, n. 115, 2012, p. 129135 .

In médio stat virtus - Außenhaftung virtueller Unternehmen. Magisterarbeit. Frankfurt: Johann Wolfgang Goethe Universität, Fachbereiech Rechtswissenschaft, 2002.

Arbitragem, lex mercatoria e direito estatal: uma análise dos conflitos ortogonais no direito transnacional. São Paulo: Quartier Latin Do Brasil, 2010.

MIRAVALIS, Jaume Martí. Los códigos de conducta em las redes de franquicia: el modelo americano 'versus' el europeo, Revista de derecho mercantil, n. 269, 2008, p. 949994.

Redes de distribuición: régimen jurídico de las inversiones. In: RUIZ PERIS, Juan Ignacio (Coord). Nuevas Perspectivas Del Derecho De Redes Empresariales. Valencia: Tirant lo Blanch, 2012, p.547-572.

- Transparencia y redes empresariales. In: RUIZ PERIS, Juan Ignacio (Coord). Hacia un derecho para las redes empresariales. Valencia: Tirant Lo Blanch, 2009. p.135-163. 
MITCHELL, Catherine. Contract Law and Contract Practice. Bridging the Gap Between Legal Reasoning and Commercial Expectation. Oxford: Hart Publishing, 2013.

. Leading a Life of its Own? The Roles of Reasonable Expectation in Contract Law. Oxford Journal of Legal Studies 23 (4), p. 639-665.

MÖLLER, Cosima. Der franchisevertrag im bürgerlichen rech - ein beitrag zur diskussion über die rechtsnatur des franchiesevertrages. In: Archiv für civilistische Praxis, vol. 203, n. 3, June 2003, p. 319-347.

MONTEIRO, Antonio Pinto. Contratos de distribuição comercial. Coimbra: Almedina, 2009.

MÖSCHEL, Wernhard. Dogmatische strukturen des bargeldlosen zahlungsverkehrs. In: Archiv für civilistische praxis, vol. 186, 1986, p. 187-236.

MOSCO, Gian Domenico. Frammenti ricostruttivi sul contratto di rete. In: Giurisprudenza commerciale, 2010, volume 37, fascicolo 6, parte 1, p. 839-863.

MÖSLEIN, Florian. Contract governance within corporate governance: a lesson from the global financial crisis. In: GRUNDMANN, Stefan; CAFAGGI, Fabrizio; VETTORI, Giuseppe (Coord.). The organizational contract: from exchange to long-term network cooperation in European contract law. London: Ashgate, 2013, p. 293-315.

MOUSSERON, Pierre: et alli. Les usages: l'autre droit de l'entreprise, Paris: LexisNexis, 2014.

MÜLLER-HAGEDORN, Lothar. The variety of distribution systems. In: Journal of Institutional and Theoretical Economics, vol. 151, 1995, p. 186-202.

MUNHOZ, Eduardo Secchi. Empresa contemporânea e direito societário. Poder de controle e grupos de sociedades. São Paulo: Ed. Juarez de Oliveira, 2002.

MUNÕZ, Pablo Jarne. Aprovisionamiento y stock em los contratos de distribución 
integrada. Madrid: Reus, 2016.

MUSSI, Luiz Daniel Haj. Abuso de dependência econômica nos contratos interempresariais de distribuição. Dissertação de mestrado. USP, São Paulo, 2007.

MUSSO, Alberto. Reti contrattuali fra imprese e trasferimento della conoscenza innovativa. In: IAMICELI, Paola (Coord.). Le reti di imprese e $i$ contratti di rete. Torino: Giappichelli, 2009. p.177-224.

NANNI, Giovanni Ettore; LOTUFO, Renan. (Coord.) Teoria geral dos contratos. São Paulo: Atlas, 2011.

NEBEL, Jürgen; GAJEWSKI, Karen. Die Gremien des Franchisesystems. In: NEBEL, Jürgen; SCHULZ, Albrecht; FLOHR, Eckhard (Org.). Das Franchise-System. Handbuch für Franchisegeber und Franchisenehmer, 4. Auflage, München: Verlag Vahlen, p. 375-383.

NERVI, Andrea. I contratti di distribuzione: tra causa di scambio e causa associativa, Napoli: Edizioni Scientifiche Italiane, 2011.

NERY JR., Nelson. Contrato de distribuição de petróleo e derivados (Parecer). Idem: Soluções práticas de direito, vol. 2, São Paulo: RT, 2010, p. 443 - 475 - documento eletrônico).

NETO, Alfredo de Assis Gonçalves. Empresa individual de responsabilidade limitada e sociedade de pessoas. In: CARVALHOSA, Modesto (Coord.). Tratado de direito empresarial, São Paulo: RT, 2016, vol. II.

NETO, Humberto Theodoro. Efeitos externos do contrato: direitos e obrigações na relação entre contratantes e terceiros. Rio De Janeiro: Forense, 2007.

NICKLISCH, Fritz. Rechtliche erfassung von projektabläufen und projekstörungen bei komplexen langzeitverträge. In: NICKLISCH, fritz. (Coord.) Der komplexe langzeitvertrag: strukturen und internationale schiedsgerichtsbarkeit/the complex longterm contract: structures and international arbitration - heidelberger kolloquium 
technologie und recht 1986. Heidelberg: C.F. Müller Juristischer Verlag, 1987, p. 365-375.

NICKLISCH, Fritz. Vorteile einer dogmatik für komplexe langzeitverträge. In: NICKLISCH, Fritz. (Coord.) Der komplexe Langzeitvertrag: Strukturen und Internationale Schiedsgerichtsbarkeit/The Complex Long-Term Contract: Structures and International Arbitration - Heidelberger Kolloquium Technologie und Recht 1986. Heidelberg: C.F. Müller Juristischer Verlag 1987, p. 17-28.

NOLL, Jürgen. Who should be liable in a virtual enterprise network. In: Discussion Paper, July 2002. Disponível em http://ssrn.com/abstract=319965, acesso em 10.02.2014.

NORTH, Douglass C. Institucions, institucional change and economic performance. 26rd ed., New York: Cambridge University Press, 2006.

OECHSLER, Jürgen. Gerechtigkeit im modernen Austauschvertrag: Die theoretischen Grundlagen der Vertragsgerechtigkeit und ihr praktischer Einflu $\beta$ auf Auslegung, Ergänzung und Inhaltskontrolle des Vertrages. Tübingen: Mohr Siebeck, 1997.

Wille und vertrauen im privaten austauschvertrag: die rezeption der theorie des relational contract im deutschen vertragsrecht in rechtsvergleichender kritik. In: Rabels Zeitschrift für ausländisches und internationales, Privatrecht/The Rabel Journal of Comparative and International Private Law, Bd. 60, ,1996, p. 91-124.

OETKER, Hartmut. Das dauerschuldverhältnis und seine beendigung: bestandsaufnahme und kritische würdigung einer tradierten figur der schuldrechtsdogmatik. Tübingen: Mohr Siebeck, 1994.

OTT, Claus. Contract Network in Distribution Systems. In: Journal of Institutional and Theoretical Economics, vol. 151, 1995, p. 212-217.

OUDIN, Martin. La transmission des contrats de distribution. In: Revue Trimestreille de Droit Commercial, n. 3, 2011, p. 447-462.

PALHARES, Cinara Interpretação dos grupos de contratos nas joint ventures. Revista 
jurídica empresarial, Porto Alegre, ano 2, nº9, p.177-221. jul./ago. 2009.

PAOLA, Leonardo Sperb de. Contratos de distribuição: vida e morte da relação contratual. Tese de Doutorado. Universidade Federal do Paraná, 2001.

PARDOLESI, Roberto. Conclusioni. In: GITTI, Gregorio; VILLA, Gianroberto. (Coord.) Il terzo contrato. Bologna: Il Mulino, 2008. p.00-00.

PELLE, Sébastien. La notion d'interdépendance contractuelle, contribution à l'étude des ensembles de contrats. Paris: Dalloz, 2007.

PENTEADO, Luciano de Camargo. Causa concreta, qualificação contratual, modelo jurídico e regime normativo: notas sobre uma relação de homologia a partir de julgados brasileiros. In: CUNHA, Alexandre dos Santos. (Coord.) O direito da empresa e das obrigações e o novo Código Civil brasileiro. São Paulo: Quartier Latin, 2006. p. 249-287.

Efeitos contratuais perante terceiros. São Paulo: Quartier Latin, 2007.

- Redes contratuais e contratos coligados. In: TARTUCE, Flávio; HIRONAKA, Giselda Maria Fernandes Novaes (Coord.). Direito contratual: temas atuais. São Paulo: Método, 2008. p.463-492.

PEREIRA, Caio Mário da Silva. Instituições de direito civil. vol. III. Rio de Janeiro: Forense, $10^{a}$ ed., 1999.

PEREIRA, Guilhemer Döring Cunha. Alienação de poder de controle acionário. São Paulo: Saraiva, 1995.

PERIS, Juan I. Ruiz. Business network as a legal explanatory framework. In: GRUNDMANN, Stefan; HAAR, Brigitte; MERKT, Hanno (Coord.). Festschrift für Klaus J. Hopt zum 70. Geburtstag am 24. August 2010. Unternehmen, Markt und Verantwortung. Berlin: De Gruyter, 2010, p. 2901-2917. Un derecho específico para las redes empresariales. In: PERIS, Juan I. Ruiz. 
(Coord.). Nuevas perspectivas del derecho de redes empresariales. Valencia: Tirant lo Blanch, 2012, p. 73-124.

PERLINGIERI, Pietro. Autonomia negoziale e autonomia contrattuale: estratto da manuale di diritto civile. Napoli: Edizioni Scientifiche Italiane, 2014.

Reti i contratti tra imprese tra cooperazione e concorrenza. In: IAMICELI, Paola. Le reti di imprese e i contratti di rete. Torino: Giappichelli, 2009. p.387-399.

PERONE, Gianluca. L'interesse consortile, Milano: Giuiffrè, 2008.

PESKINE, Elsa. Réseaux d'entreprises et droit du travail. Paris: L.G.D.J., 2008.

COSTA, Philomeno J. da. Resenha à obra Grupos de Sociedades y acionistas minoritários, de Autor. In Revista de direito mercantil, industrial, econômico e financeiro, RT, São Paulo, n. 78, 1990, p. 81.

PIGASSOU, Paul. La distribution intégrée. In: Revue Trimestreille de Droit Commercial et de Droit Économique, n. 3, 1980, p. 473-544.

PINTO, Fernando A. Ferreira. Contratos de distribuição: Da tutela do distribuidor integrado em face da cessação do vínculo. Lisboa: Universidade Católica Editora, 2013.

PINTO, Paulo Mota. Declaração tácita e comportamento concludente no negócio jurídico. Coimbra: Almedina, 1995.

Interesse contratual negativo e interesse contratual positivo - volume 1. Coimbra: Coimbra Editora, 2008.

POMAR, Fernando Gomes; GOLOBARDES, Mireia Artigot i. Long-term contracts in the law and economics literature. In: DE GEEST, Gerrit (ed). Contract law and economics. Second Edition, Cheltenham Glos: Edward Elgar, 2011, p. 314-359. 
POSNER, Richard. The law and economics of contract interpretation. In: Texas law review, v. 83, 2005, p. 1581-1614.

POWELL, Walter W. Neither market nor hierarchy: network forms of organizations. In: Research in organizational behavior, $\mathrm{n}^{\circ}$ 12, 1990, 295-336, disponível em http://www.stanford.edu/ woodyp/paper_index.htm.

PROENÇA, José Marcelo Martins. A exclusão de sócio nas sociedades limitadas. In: FINKELSTEIN, Maria Eugênia Reis; (Coord.). Tipos societários. São Paulo: Saraiva, 2009, p. 173-205.

PROSENJAK, Jonatam. Economic analysis of value-added networks: a holistic approach to the competitive effects of vertical agreements. In: JUNG, Stefanie; KREBS, Peter; TEUBNER, Gunther (Coord.). Business networks reloaded. Baden-Baden: Nomos, 2015, p. 227-259.

QUESADA, Carmen Estevan de. El abuso de dependência económica en las redes de distribución. In: RUIZ PERIS, Juan Ignacio. Hacia un derecho para las redes empresariales. Valencia: Tirant Lo Blanch, 2009. p.187-223.

REALE, Miguel. Característicos do contrato de concessão comercial (Parecer). In: Questões de direito privado. São Paulo: Saraiva, 1997, p. 183-189.

Sistema normativo das concessões comerciais de veículos automotivos. In: Questões de direito privado, São Paulo: Saraiva, 1997, p. 149-181.

REQUIÃO, Rubens. Contrato de concessão comercial com exclusividade de postos de revenda de gasolina (Parecer). In: FRANCESCHINI, José Inácio Gonzaga; FRANCESCHINI, José Luiz Vicente de Azevedo (Coord.). Poder econômico: exercício e abuso- direito antitruste brasileiro. São Paulo: RT, 1985, p. 595-609.

Curso de direito comercial, São Paulo: Saraiva, 22ª ed., 1995, $1^{\circ}$ vol. O contrato de concessão de venda com exclusividade (concessão comercial). 
Revista de direito mercantil, industrial, econômico e financeiro, São Paulo, n. 7, ano xi, p.17-45, 1972.

RIBEIRO, Adir; GALHARDO, Maurício; MARTI, Leonardo; IMPERATORE, Luis Gustavo: et alli. Gestão estratégica do franchising: como construir redes de franquias de sucesso. São Paulo: DVS editora, 2013.

RIBEIRO, Maria de Fátima. $O$ contrato de franquia (franchising). Coimbra: Almedina, 2001.

RICHARD, Sophie-Anna. L'appartenance à um réseau de distribution: contribution à l'étude des réseaux, Universite Montpellier 1, These, 2012.

RODOTÁ, Stefano. Códigos de conducta: entre hard law e soft law. In: ALICIA REAL PÉREZ (Coord.). Códigos de conducta y actividad económica: una perspectiva jurídica. Madrid: Marcial Pons, 2010, p. 26.

ROHE, Mathias. Netzverträge: rechtsprobleme komplexer vertragsverbindungen. Tübingen: Mohr Siebeck, 1998.

RUIZ PERIS, Juan Ignacio (Coord.). Nuevas perspectivas del derecho de redes empresariales. Valencia: Tirant Lo Blanch, 2012.

. Del contrato bilateral a la relación de red. In: (Coord.) Hacia un derecho para las redes empresariales. Valencia: Tirant Lo Blanch, 2009. p.9-20. Intromisión en la clientela ajena y redes de distribución (encroachment). Cizur Menor (Navarra): Thomson Aranzadi, 2007.

. Un derecho específico para las redes empresariales. In: . (Coord.). Nuevas Perspectivas Del Derecho De Redes Empresariales. Valencia: Tirant Lo Blanch, 2012. p.73-124. 
RULLANI, Enzo; PALMIERI, Domenico. Reti d'impresa oltre i distretti: nuove forme di organizzazione produttiva, di coordinamento e di assetto giuridico. Milano: Il Sole 24 Ore, 2008.

SABEL, Charles. F.; ZEITLIN, Jonathan. Neither Modularity nor Relational Contracting: Inter-Firm Collaboration in the Net Economy. In: Enterprise and society, vol. 5, no 3, 2004, p. 388-403.

SACCO, Rodolfo. DE NOVA, Giorgio. Il contratto. Torino: UTET, 2004.

SALOMÃO FILHO, Calixto. Breves acenos para uma análise estruturalista do contrato. In: Revista de direito mercantil, vol. 43, nº 141, jan./mar. 2006, p. 7-30.

Cláusulas de exclusividade nos contratos de representação comercial. Aspectos concorrenciais. In: BUENO, José Hamilton; MARTINS, Sandro G. (Coord.). Representação comercial e distribuição. 40 anos da Lei n. 4.886/65 e as novidades do CC/02 (arts. 710 a 721). EC 45/04: estudos em homenagem ao Prof. Rubens Requião. São Paulo: Saraiva, 2006, p. 444-468.

Direito concorrencial. São Paulo: Malheiros Editores, 2013.

- Função social do contrato: primeiras anotações. In: Revista de direito mercantil, industrial, comercial e econômico, v. 132, 2003, p. 8-24.

O novo direito societário. São Paulo, SP: Malheiros Editores, 2006.

SANTAGATA, Renato. Il "contratto di rete" fra (comunione di) impresa e società (consortile). In: Rivista di diritto civile, n. 3, 2001, p. 323-359.

SANTOS, Felipe Cassiano dos. Estrutura associativa e participação societária capitalística. Coimbra Editora: Coimbra, 2006.

SAYAG, Alain (Coord.). Le contrat cadre. Tome 1, exploration comparative; et tome 2, la distribution. Paris (CREDA): Litec, 1995. 
SCALERA, Domenico; ZAZZARO, Alberto. Do Inter-Firm Networks Make Access to Finance Easier? Issues and Empirical Evidence. In: CAFAGGI, Fabrizio (Coord.). Contractual networks, inter-firm cooperation and economic growth. Cheltenham Glos: Edward Elgar, 2011, p. 39-65.

SCHANZE, Erich. Symbiotic Arrangements. In: Journal of Institutional and Theoretical Economics, vol. 149, 1993, p. 691-697.

Symbiotic Contracts: Exploring Long-Term Agency Structures Between Contract and Corporation. In: JOERGES, Christian. (Coord) Franchising and the law: theoretical and comparative approaches in Europe and the United States - Das Recht des Franchising: konzeptionelle, rechtsvergleichende und europarechtliche Analysen. BadenBaden: Nomos Verlagsgesellschaft, 1991.p. 67-103.

SCHIMANSKY, Annika. Der Franchisevertrag nach deutschem und niederländischem Recht. Tübingen: Mohr \& Siebeck, 2003.

SCHLOTKE, Helmut. Mitwirkungspflichten bei Langzeitverträgen. In: NICKLISCH, Fritz. (Coord.) Der komplexe Langzeitvertrag: Strukturen und Internationale Schiedsgerichtsbarkeit/The Complex Long-Term Contract: Structures and International Arbitration - Heidelberger Kolloquium Technologie und Recht 1986. Heidelberg: C.F. Müller Juristischer Verlag 1987. p. 377-390.

SCHMIDT, Karsten. Gesellschaftsrechts. Berlin: Carl Heymanns Verlag, 4a Auflage, 2002.

Handelsrecht, Berlin: Carl Heymanns Verlag, 5a Auflage, 1999.

SCHWARTZ, Alan; SCOTT, Robert E. Contracts interpretation redux. In: The Yale law journal, v. 119, 2010, p. 926-964.

SCIARRA, Silvana. Franchising and contract of employement: notes on a still impossible assimilation. In: JOERGES, Christian. (Coord.) Franchising and the law: 
theoretical and comparative approaches in Europe and the United States - Das Recht des Franchising: konzeptionelle, rechtsvergleichende und europarechtliche Analysen. BadenBaden: Nomos Verlagsgesellschaft, 1991, p.239-266.

SCIGNAMIGLIO, Claudio. Dal collegamento negoziale alla causa di coordinamento nei contratti tra imprese. In: IAMICELI, Paola. Le reti di imprese e i contratti di rete. Torino: Giappichelli, 2009. p.61-76.

$\underline{\text { SCOTT, Robert. A theory of self-enforcing indefinite agreements. In: Columbia Law }}$ Review, v. 103, n. 7, 2003, p. 1641-1699. . Conflict and cooperation in long-term contracts. In: California Law Review, v. 75, 2005 (1987), p. 2005-2054.

SILVA, Juliana Pedreira da. Contratos sem negócio jurídico: crítica das relações contratuais de fato. São Paulo: Atlas, 2011.

SIMIONI, Rafael Lazzarotto. Direito empresarial nas organizações em rede: decisão, planejamento e risco. In: Revista jurídica, Curitiba, 2005, nº 18, Temática nº 2, p. 167-195.

SIRENA, Pietro. (a cura di). Il diritto dei contratti di impresa. Milano: Giuffrè, 2006. ; STUDI, Universita Degli. Il diritto europeo dei contratti d'impresa: autonomia negoziale dei privati e regolazione del mercato: convegno di studio, siena, 22 24 settembre 2004. Milano: Giuffre, 2006.

SKAUPY, Walther. Franchising: Handbuch für die Betriebs- und Rechtspraxis, München: Verlag Franz Vahlen, 2. Auflage, 1995.

SODA, Giuseppe. Reti tra imprese. Modelli e prospecttive per una teoria del coordinamento. Roma: Carocci, 1998.

STOFFELS, Markus. Gesetzlich nicht geregelte Schuldverträge: Rechtsfindung und Inhaltskontrolle. Tübingen: Mohr Siebeck, 2001. 
SYDOW, Jörg. Strategische Netzwerke. Evolution und Organisation. Berlin: Springer Gabler, 1992.

SZTAJN, Rachel. Contrato de sociedade e formas societárias. São Paulo: Saraiva, 1989.

. Suply Chain e Incompletude Contratual. In: Systemas: revista de ciências jurídicas e econômicas, vol. $1, \quad \mathrm{n}^{\mathrm{o}} \quad 1, \quad 2009$, disponível em: http://cepejus.libertar.org/index.php/systemas/article/viewarticle/10.

_. Teoria jurídica da empresa: atividade empresária e mercados. São Paulo: Atlas, 2004.

TEUBNER, Gunther. And if I by beelzebub cast out devils,...: and essay on the diabolics of network failure. In: GRUNDMANN, Stefan; CAFAGGI, Fabrizio; VETTORI, Giuseppe (Coord.). The organizational contract: from exchange to long-term network cooperation in european contract law. Surrey: Ashgate, 2013. p.113-135.

; AMSTUTZ, Marc. Editorial zum Schwerpunkt Vertragsnetze: Rechtsprobleme vertraglicher Multilateralität. In: Kritische Vierteljahresschrift für (KritV), vol. 89 (2006), p. 103-104.

Coincidentia oppositorum: hybrid networks beyond contract and organisation. In: AMSTUTZ, Marc; (Coord.). Networks: Legal Issues of Multilateral Co-operation. Oxford: Hart Pub, 2009. p.3-30.

Hybrid laws: constitutionalizing private governance networks. In: KAGAN, Robert; KRYGIER, Martin; WINSTON, Kenneth. (Coord.). Legality and community: on the intellectual legacy of Philip Selznick. Berkeley: Berkeley Public Policy Press, 2002, p. 311-331.

. Networks as connected contracts. Tradução: Michelle Everson. Oxford: Hart Publishing, 2011. 
. Unitas multiplex: corporate governance in group enterprises. In:

SUGARMAN, David. (Coord.). Regulating Corporate Groups in Europe. Baden-Baden: Nomos, 1990, p. 67-104.

TEYSSIÉ, Bernard. Les groupes de contrats, thèse Montpellier. Paris: L.G.D.J., 1975.

THEODORO JR., Humberto. e ADRIANA MANDIM THEODORO DE MELLO, O regime o contrato (típico) de agência e distribuição (representação comercial) no novo Código Civil em cotejo com a situação jurídica do contrato (atípico) de concessão comercial. Indenizações cabíveis na extinção da relação contratual, Revista dos Tribunais, vol. 825, p. 35-74, documento eletrônico.

THORELLI, Hans. Networks: between markets and hierarchies. In: Strategic Management Journal, v. 7, 1986, p. 37-51.

TIROLE, Jean. Incomplete contracts: where do we stand? In: Econometrica, v. 67, n. 4, 1999, p. 741-781.

TORGER REVE, Torger; STERN, Louis W. Interorganizational Relations in Marketing Channels. In: The Academy of Management Review, Vol. 4, n. 3, 1979, p. 405416.

TOURNEAU, Philippe Le. Les contrats de concession, 2a. ed., Paris: LexisNexis, 2010 . Les contrats de franchisage, 2a. ed., Paris: LexisNexis, 2007.

ULMER, Peter. Der Vertragshändler, München: C.H. Beck, 1969, p. 143.

UZZI, Brian. The sources and consequences of embeddedness for the economic performance of organizations: the network effect. American Sociological Review. vol. 61, 1996, p. 674-698. 
VASCONCELOS, Pedro Pais de. Contratos atípicos. Coimbra: Livraria Almedina, 1995.

VERÇOSA, Haroldo Malheiros Duclerc. Curso de direito comercial, São Paulo: Malheiros, 2006, vol. 2.

Contratos mercantis e a teoria geral dos contratos: o Código Civil de 2002 e a crise do contrato. São Paulo: Quartier Latin, 2010.

VETTORI, Giuseppe. Contratto di rete e sviluppo dell'impresa. In: Obbligazioni e contratti, 2009, vol. 5, fascicolo 5, p. 390-396

VIEIRA, José Alberto. O contrato de concessão comercial. Coimbra: Coimbra editora, 2006 (reimpressão).

VILLA, Gianroberto. Il coordinamento interimprenditoriale nella prospettiva del contratto plurilaterale. In: PAOLA IAMICELI (Coord.). Le reti di imprese e $i$ contratti di rete. Torino: Giappichelli, 2009, p. 103-130.

VINCELLES, Carole Aubert de. Linked contract under french Law. In: CAFAGGI, Fabrizio (ed). Contractual networks, inter-firm cooperation and economic growth. Cheltenham Glos: Edward Elgar, 2011, p. 163-178.

VIO, Daniel de Avila. Grupos Societários. Ensaio sobre os grupos de subordinação, de direito e de fato, no direito societário brasileiro. São Paulo: Quartier Latin, 2016.

VIRASSAMY, Geoger J. Les contrats de dépendance, Essai sur les activités professionnelles exercées dans une dépendance économique, thèse. Paris: L.G.D.J., 1986.

WAUSCHKUHN, Ulf. Der Vertragshändlervertrag, $3^{\mathrm{a}}$ ed., München: C.H. Beck, 2009.

WEITZENBOECK, Emily M. A legal framework from emerging business models: dynamic networks as collaborative contracts. Cheltenham: Edward Elgar, 2012. 
WELLENHOFER, Marina. Third party effects of bilateral contracts within the network. In: AMSTUTZ, Marc; TEUBNER, Gunther (Coord.). Networks: legal issues of multilateral co-operation. Oxford: Hart Pub, 2009. p.119-136.

WHITTAKER, Simon. Contract networks, freedom of contract and restructuring of privity of contract. In: CAFFAGI, Fabrizio. Contractual networks, inter-firm cooperation and economic growth. Cheltenham: Edward Elgar, 2011. p.179-197.

WIEDEMANN, Herbert; SCHULTZ, Oliver. Grenzen der Bindung bei langfristigen Kooperationen. In: Zeitschrift für Wirtschaftsrecht, ano 20, 1999, p. 01-12.

WIELAND, Karl. Handelsrecht, vol. II, Die Kapitalgesellschaften, München: Duncker \& Humblot, 1931.

WIGHTMAN, John. Beyond costum: contract, contexts, and the recognition of implicit understandings. In: ; CAMPBELL, David. (Coord.) Implicit dimensions of contract: discrete, relational and network contracts. Oxford: Hart Publishing, 2003, p. 143-186.

WILLIAMSON, Oliver E. Assessing Vertical Market Restrictions: Antitrust Ramifications of the Transaction Cost Approach, University of Pennsylvania Law Review, Vol. 127, No. 4, 1979, p. 953-993.

. Calculativeness, Trust, and Economic Organization. In: The mecanisms of governance. New York: Oxford University Press, 1996, p. 250-278.

- "Comparative economic organization: the analysis of discrete structural alternatives”. In: The Mechanisms of Governance. Oxford University Press, 1996, p. 93-119 . Networks - organizational solutions to future challenges. In: THEURL, Theresia (Coord.). Economics of interfirm networks. Tübingen: Mohr Siebeck, 2005, p. 327. 
. The economic institucions of capitalism: firms, markets, relational contracting. New York: The Free Press, 1985.

The theory of the firm as governance structure: from choice to contract. In: Journal of economics perspectives, v. 16, n. 3, 2002, p. 171-195.

. Transaction Cost Economics: The Governance of Contractual Relations. In: Journal of law and economics, vol. 22, nº 2 (october 1979), p. 233-261.

.Why, Law, Economics and Organizations? (December 2005). Annual review of law and social science, vol. 1, Dec/2005. p. 369-396, disponível em: http://www.annualreviews.org/doi/pdf/10.1146/annurev.lawsocsci.1.031805.111122.

WOLF, Manfred. The protection of contractual networks agains interference by third parties. In: AMSTUTZ, Marc; TEUBNER, Gunther. Networks: legal issues of multilateral co-operation. Oxford: Hart Pub, 2009. p.225-240.

; UNGEHEUER, Christina. Vertragsrechtliche Probleme des Franchising. Betriebs-Berater: Zeitschrift für Recht und Wirtschaft, 49 (1994), p. 1027-1033.

ZANARONE, Giorgio. Influenza unilaterale sul contratto ed efficenza organizzative: un'analisi empirica dei contratti di distribuzione automobilistica. In: CAGAFFI, Fabrizio. (a cura di) Corporate governance, networks e innovazione. Trento: Cedam, 2005. p. 135-159.

ZORZI, Andrea. Reti di imprese e modelli societari di coordinamento. In: CAFAGGI, Fabrizio. Reti di imprese tra regolazione e norme sociali: nuove sfide per diritto ed economia. Bologna: Il Mulino, 2004. p.177-231.

ZWANZGER, Michael. Der mehrseitige Vertrag. Tübingen: Morh Siebeck, 2013.

ZWECKER, Kai-Thorsten. Franchising als symbiotischer Vertrag: Beziehungen zwischen Gesellschaftsrecht und Franchising. In: Jusistiche Arbeitsblätter, ano 31, 1999, p. 159-164. 
ZYLBERSZTAJN, Decio; SZTAJN, Rachel (ORG). Direito \& economia: análise econômica do direito e das organizações. Rio de Janeiro: Elsevier, 2005. 